\title{
Corpus
}

Archivos virtuales de la alteridad americana

Vol 3, No 2 | 2013

Julio / Diciembre 2013

\section{Archivos y memorias. El caso "Vigil" y el corpus (re) aparecido}

Archives and memories. The (re)appeared corpusand the "Vigil"case

\section{Natalia García}

\section{OpenEdition}

\section{Journals}

Edición electrónica

URL: http://journals.openedition.org/corpusarchivos/524

DOI: 10.4000/corpusarchivos.524

ISSN: $1853-8037$

Editor

Diego Escolar

Referencia electrónica

Natalia García, "Archivos y memorias. El caso "Vigil" y el corpus (re) aparecido », Corpus [En línea], Vol 3, No 2 | 2013, Publicado el 20 diciembre 2013, consultado el 01 mayo 2019. URL : http:// journals.openedition.org/corpusarchivos/524; DOI : 10.4000/corpusarchivos.524

Este documento fue generado automáticamente el 1 mayo 2019.

Licencia Creative Commons: Atribución-NoComercial 2.5 Argentina (CC BY-NC 2.5 AR) 


\title{
Archivos y memorias. El caso "Vigil" y el corpus (re) aparecido
}

\author{
Archives and memories. The (re)appeared corpusand the "Vigil"case
}

\author{
Natalia García
}

\section{NOTA DEL EDITOR}

Fecha de recepción del original: 21/11/2012

Fecha de aceptación para publicación: 08/08/2013

\section{Introducción}

1 El presente artículo se desprende de una investigación académica inscripta en el campo de la historia reciente de la educación argentina. Iniciada en el año 2008, examina en profundidad la intervención dictatorial sobre la emblemática Biblioteca "Constancio C. Vigil" de Rosario producida el día 25 de febrero de 1977. Su validación empírica resultó del cruce permanente de fuentes orales y documentales; esto es, recurriendo a entrevistas en profundidad y por vía de una exhaustiva búsqueda de fondos documentales de orden secundario y primario ${ }^{1}$. Desde un inicio, estos últimos fueron concebidos como materiales determinantes para la factibilidad de la indagación en cuanto a la producción de nuevos conocimientos sobre el caso; principalmente, al observar que en las publicaciones anteriores $^{2}$ predominaban los testimonios orales y/o datos duros documentados pero desprovistos de un análisis que profundizara en algunas de sus múltiples tramas, como veremos: económico-financieras; político-ideológicas; pedagógicas, u orientadas a su dinámica sociocultural ciertamente popular. En particular, se entiende que los trabajos de Naranjo (1991) y Frutos (1997), ex miembros de la Comisión Directiva (CD) de la entidad, gradualmente devinieron en una novela institucional (Fernández, 1994) transmitida en cuantiosas prácticas de divulgación, como también en investigaciones académicas. 
2 En rigor, el relato anterior se articuló solidariamente a la potente representación de una pérdida total de las pruebas de institucionalidad, producto de la destrucción dictatorial. A modo de ejemplo, puede citarse al historiador Malla refiriendo el desalentador cuadro: “(...) los miembros de la Biblioteca Vigil no se preocuparon por escribir su propia historia y cuando quisieron hacerla se encontraron con que todos los documentos habían sido destruidos por la intervención militar de 1977" (2006, p.153). Ciertamente, ambos señalamientos son falaces. Por un lado, resulta extraño que el autor no advierta la nota metodológica que Naranjo agrega en el apartado "Bibliografía"; allí puede leerse: "Para escribir este trabajo se apeló, fundamentalmente, a documentos elaborados en la Biblioteca Popular Constancio C. Vigil" (1991, p. 24). En cuanto a la "despreocupación" planteada, no cabe más que volver a citar los textos de Naranjo y Frutos $(1991,1997,2006)$ como (pre)ocupación efectiva para una reconstrucción de "su propia historia". Vale decir, la novela se puede debatir con rigurosidad historiográfica pero no se puede ignorar, pues sabido es que las memorias, y más aún los olvidos, expresan la permanencia deliberada de una producción de sentidos históricos que se deben reflexionar y revisar.

3 Aunque cardinales, los extensos debates en torno de los usos de las memorias y roles de la historia no son materia de análisis en estas páginas; mejor decir, no son asunto de discusión per se sino articulado a un punto neurálgico: el positivo encuentro de diversos y heterogéneos archivos de "la Vigil", y con ello, la caída del supuesto desierto documental. Acervos asimismo significativos no solo en cantidad sino en calidad de masa crítica para la producción de nuevos saberes sociopolíticos en torno de su dimensión organizacional, para una revisión de sus tramas pedagógicas y, fundamentalmente, para alcanzar un diálogo profundo entre la experiencia institucional y los escenarios históricos por los cuales discurrió. Con ello, un interrogante surca con sentido la dimensión descriptiva que inevitablemente predomina en este artículo, a saber: ¿Por qué -aparentemente-el caso trasunta desde el silencio documental a la proliferación de fuentes escritas? Si las significaciones que se hacen del pasado parten de las preocupaciones presentes, y éste se configura en arreglo con las elaboraciones del pasado, ¿acaso la irrupción de los documentos solo responde a un tiempo sociopolítico favorable?

Para una cabal comprensión tanto del marco histórico contextual como de las depuraciones documentales consumadas, se considera prioritario presentar un resumen de la historia institucional que en gran medida ya lleva consigo los aportes novedosos del corpus "(re)aparecido".

\section{El caso "Vigil": Génesis y crecimiento institucional}

5 Los inicios de la Biblioteca Vigil se enlazan a la Asociación Vecinal del barrio "Tablada y Villa Manuelita" en la zona sur de Rosario, creada (1933) al calor del movimiento asociacionista. Hacia al año 1953, un entusiasta grupo de adolescentes y jóvenes se sumó al espacio barrial y conformó una Subcomisión de Biblioteca. De entre ellos, en 1958 surgió una idea inédita y sencilla que operó como punto de inflexión: organizar y administrar una rifa "pagadera en cuotas". Esta resultó exitosa desde su implementación; en pocos años, su crecimiento fue sostenido y exponencial. En gran medida, ello se debió a la combinatoria de abonarla en forma accesible, ofrecer atrayentes premios y sostener la promesa de dirigir la recaudación hacia un conjunto de actividades y servicios sociales, educativos y culturales significativos en su comunidad. Encontrados los recursos financieros, en 1959 el grupo juvenil se independizó constituyendo la Asociación civil 
"Biblioteca Constancio C. Vigil". En adelante, creció y se desarrolló de forma embrionaria; es decir, la concreción de cada proyecto fue fruto del cruce de un específico interés grupal o particular, y las reales posibilidades de autogestionarlo. Bajo esta tendencia y durante la década del 60 surgieron: el Jardín de infantes, el Servicio Bibliotecario, la Editorial, el Museo de Ciencias Naturales, el Observatorio Astronómico, la Universidad Popular, un Centro Recreativo, Cultural y Deportivo, la Caja de Ayuda Mutua, la Guardería y el Centro Materno Infantil ${ }^{3}$. Llegada la década del 70 , la organización inauguró el Instituto Secundario y la Escuela primaria; ambos de carácter gratuito, mixto, laico y de jornada extendida o doble escolaridad; al tiempo que se oficializaron los establecimientos de nivel inicial (Central y Anexos en Villa Manuelita) en marcha desde el año 1960.

6 Lo anterior resultó materialmente posible por cuanto en 1965 las rifas se transformaron en bonos bianuales que extendieron su venta en variadas y lejanas regiones del territorio nacional ${ }^{4}$; indudablemente, la cifra de 3.000 vendedores y 500 cobradores evidencia el éxito de su comercialización y las razones de sus millonarios ingresos mensuales. Así, Biblioteca Vigil se erigió en un complejo social, cultural y educativo de proporciones únicas que abandonó el régimen normativo asociacionista para acoplarse al movimiento mutualista. De unas prácticas altruistas del tiempo libre, devino en una entidad cooperativa de sólido capital financiero y patrimonial dirigida por una CD cuyos miembros permanecieron en iguales funciones hasta el año 1977, por vía del voto mayoritario de la masa de 19.639 asociados, y asignándose un salario mensual que no superaba el $1.5 \%$ de diferencia monetaria entre el máximo cargo y último puesto en el escalafón compuesto por 647 empleados. La obra educativa resultó su proyecto más potente con casi 3.000 alumnos en sus escuelas formales y no formales de todos sus niveles.

\section{Crisis financiera, intervención y genocidio cultural (1974-1977)}

7 Los fuertes cimbronazos económicos de los años 1974-1975 afectaron severamente los engranajes financieros de la institución. Por un lado, hacia el segundo semestre de 1974 comenzó en Argentina una escalada inflacionaria que el gobierno de Isabel Martínez de Perón (1974-1976) intentó controlar impidiendo la suba de precios. Algunos sectores empresariales respondieron con la paralización total de entrega de mercaderías y durante ocho meses la entidad quedó desabastecida de los bienes afectados a premios de los bonos o rifas previamente contratados. Por su parte, en junio de 1975 el ministro de economía Celestino Rodrigo devaluó un 150\% el peso nacional en relación al dólar comercial; subió el 100\% de todos los servicios públicos y transporte, y un 180\% los combustibles. Para "la Vigil”, la combinatoria de devaluación e inédita inflación sobrevino en una encerrona financiera que escapó a todo control interno: los programas de sorteos continuaban semanalmente a requerimiento de expresas normas legales, en tanto las mercaderías de las rifas ya vendidas no estaban disponibles. Desde ya, la licuación de los salarios de la clase trabajadora también se manifestó en la caída de las ventas de bonos en más de un 70\% para fines del año 1975. En suma, el "Rodrigazo" convirtió en deuda sus alicaídos ingresos; por primera vez en más de quince años de pujante desarrollo, la organización afrontaba un pasivo irrefrenable. 
Iniciado ya el terrorismo de Estado (1976-1983), el indefectible incumplimiento en la entrega de premios a los ganadores disparó un conjunto de demandas judiciales. Específicamente, el expediente judicial № 436/77caratulado "Biblioteca Vigil s/ Operaciones de Liquidación", se abrió en 1977 con una veintena de querellantes; una cifra ciertamente benévola con relación a los cientos de ganadores igualmente perjudicados por entonces. No obstante, estas acotadas acciones civiles resultaron suficientes y oportunas para operar como chivo expiatorio y dar inicio a una intervención fundamentada en un discurso paternalista en pro de la "salvaguarda y defensa del bien común", y apuntando las acusaciones por manejos deshonestos a la dirigencia de la organización, tal y como lo expresa el decreto de "Intervención normalizadora" № 0942/77 dictado por el entonces gobernador de facto Jorge Desimoni.

9 La normalización se puso en marcha con la toma de posesión de sus instalaciones el 25 de febrero de 1977 efectivizada por personal de servicios de seguridad (policial y militar) y civiles profesionales (contadores, abogados y escribanos). Tras solo 49 días hipotéticamente destinados a regularizar los pasivos contables, investigar posibles ilícitos cometidos por la CD, y garantizar la continuidad de la gran obra popular, finalmente se declaró la liquidación de su patrimonio y el traspaso del control institucional desde la Marina al Ejército. La Resolución No 202 puesta en vigencia el 15 de abril de 1977 fue el marco legal que habilitó su destrucción material; sus valiosos bienes muebles e inmuebles fueron quemados, desmantelados, destruidos, abandonados y subastados en remates viciados y ventas fraudulentas como ulteriormente lo detallaremos.

10 A la fecha, estas acciones habilitan denominar el proceso liquidatorio como un caso particular de genocidio cultural ${ }^{5}$ susceptible de penalidad en la figura de delitos económicos imprescriptibles. Asimismo, el pathos intervencionista se inscribe como delito de lesa humanidad en rigor de la detención ilegal y desaparición forzada de ocho miembros de la CD la madrugada del 10 de mayo de $1977^{6}$. La articulación de ambos se significa gravemente al comprender que los dirigentes desaparecidos estaban en condiciones jurídicas de avalar los procesos contables y financieros, refutar una acusación de malversación de fondos y velar por el cumplimiento transparente del injustificado proceso de quiebra y extinción de los bienes tasados en cifras millonarias, según lo detallaremos a propósito del seguimiento del ya mencionado expediente judicial.

\section{Pedagogía de la intervención}

11 El sistema escolar de Biblioteca Vigil resultó la única estructura institucional que la intervención liquidadora sostuvo hasta la transferencia de las escuelas al ámbito de la enseñanza pública provincial en 1980 y bajo la denominación "Complejo Pedro de Vega", intentando operar como último borramiento de su identidad y reconocimiento populares . En verdad, tal formalidad resultó el tramo final de un larvado proceso de militarización educativa (Kaufmann y Doval, 1997) gestado desde la primera jornada del ciclo lectivo 1977. En tal sentido, señalar la conservación edilicia y permanencia de la enseñanza formal, lejos supone una continuidad de la experiencia educativa vigente hasta la intervención. Empíricamente, las rupturas se inscriben en el cierre y desmantelamiento de las bibliotecas pedagógicas especializadas, laboratorios, gimnasios y comedor escolar; supresión del sistema de becas asistenciales; expulsión de los "directores de curso"8 (para el nivel medio); clausura de los gabinetes psicopedagógicos y el servicio médico integral. Desde ya, la desaparición del conjunto de dispositivos materiales y simbólicos, 
inéditamente orientados a los sectores más vulnerables de la ciudad, reinstalaron un escenario escolar fuertemente segmentado y vaciado de contenidos socialmente significativos que ciertamente caracterizó al periodo en cuestión (Tedesco, Braslavsky y Carciofi, 1983; Braslavsky, 1986).

Conectado a lo anterior, la alta calidad de la enseñanza que singularizaba a las escuelas "de la Vigil" disminuyó marcadamente en virtud del éxodo del cuerpo docente, distinguido por la auspiciosa combinatoria de una rigurosa formación académica y tendencia general hacia la incorporación de propuestas didácticas emparentadas a las últimas oleadas escolanovistas ${ }^{9}$. En lo particular de la escuela secundaria, el plantel quedó diezmado por renuncias masivas, producto de la violencia política desatada ya desde 1974 ${ }^{10}$, como efecto del terror dictatorial instaurado en 1976 y tras la aplicación de la Ley de Prescindibilidad (Res. 851/80), que finalmente llegó a la institución para decenas de profesores dado el traspaso de la planta docente al ámbito estatal.

Focalizando en el Instituto Secundario, y a los efectos de aproximarnos a una significación topográfica de lo que llamamos "pedagogía de la intervención", resulta prioritario connotar el desplazamiento y reemplazo de sus directivos obligados a presentar la renuncia indeclinable una vez dictada la liquidación patrimonial. Específicamente, Rubén Naranjo $^{11}$ fue sustituido en su cargo de rector por Carlos Sfulcini, y la vice dirección a cargo de la Prof. Elba Parolín ${ }^{12}$ quedó en manos del psicólogo Raúl Pangia. En lo que respecta a la coordinación de todos los niveles escolares, el reconocido pedagogo Mario López Dabat ${ }^{13}$ fue desplazado en su función de Director del Departamento de Educación. En rigor, el espacio en su conjunto dejó de existir como tal; en adelante, la gestión del complejo educativo quedó a cargo de Alcides Ibarra, especialmente enviado desde el Ministerio de Educación de la provincia de Santa Fe como "asesor pedagógico".

Nuevas fuentes documentales permiten al presente desnudar categóricamente el rostro profundo y por entonces desconocido de las nuevas autoridades ${ }^{14}$. A saber: el "asesor pedagógico" Telmo Raúl Alcides Ibarra era miembro de la policía provincial; en los años más oscuros de la historia argentina se desempeñó en el Servicio de Informaciones de la Jefatura de Policía de Rosario ${ }^{15}$ donde se hacía llamar "Rommel" por "deferencia" al famoso mariscal de campo y comandante nazi Erwin Eugen Rommel. Por su parte, Carlos Sfulcini, era llamado "Pancuca", "Carlitos" o "Carlos Bianchi" según los tiempos y lugares genocidas en los cuales también revistó; ya fuere en el centro clandestino de detención conocido como "la Quinta de Funes" en las afueras de la ciudad de Rosario "como parte del grupo operativo a cargo del Mayor Jorge Pascual Guerrieri, una combinación de Ejército (II Cuerpo) y Policía de la Provincia de Santa Fe"; o miembro "de la patota de Oroño, que no solo se ocupaba de las tareas de inteligencia sino de los operativos y gestión de algunos de los centros de detención que funcionaron en el área" (Águila, 2008a, p. 187). A diferencia de Alcides Ibarra, Sfulcini no pertenecía a ninguna fuerza de seguridad; era un joven colaboracionista alistado como Personal Civil de Inteligencia (PCI), según la nómina parcial recientemente publicada tras el decreto presidencial № $4 / 2010^{16}$. Igual situación se observa en el caso de Raúl Pangia ${ }^{17}$, tratándose incluso de un funcionario de los servicios de inteligencia con tareas anteriores al golpe de Estado de 1976; concretamente, durante la etapa reactiva y misional del ministro de educación de la nación Oscar Ivanissevich (1974-1975), el psicólogo participó de las depuraciones del personal docente de la Facultad de Psicología de la Universidad Nacional de Rosario (UNR) en 1975. Como se dijo, en abril de 1977 fue convocado para cubrir el cargo de Vicerrector en el Instituto Secundario de Biblioteca Vigil, al tiempo que también ejerció como docente 
de las asignaturas "Psicología" para cuarto y quinto año y "Formación Moral y Cívica" para el ciclo básico.

15 Asimismo, la tríada despótica que regenteó la vida escolar estuvo secundada por un subgrupo de nuevos profesores especialmente nombrados desde 1977; docentes de nivel medio y superior ideológicamente consustanciados con el régimen dictatorial en general, e institucional en particular. Es decir, fuera de los miembros del cuerpo policial o militar y civiles que participaron del terrorismo de Estado bajo el régimen del PCI, en esta escuela secundaria se repiten testimonios que registran prácticas y enunciados de un autoritarismo extremo ${ }^{18}$ que ya escapan al mero rol auxiliar que supo darse al interior de las escuelas una vez llegadas las directivas censoras ${ }^{19}$. Los testimonios identifican a estos actores como "la camarilla", en su mayoría provenientes de la universidad pública de Rosario $\mathrm{y}$, en este sentido, significado como el rostro políticamente correcto y profundamente funcional a la estrategia intervencionista; dato que ciertamente se acopla a los conocimientos cosechados en estudios que ya han indagado en el rol de los académicos (Kaufmann, 2001).

\section{El corpus (re)aparecido}

\section{El Expediente Judicial: una confesión de partes}

Gráfico $N^{\circ} 1$ : Expediente Judicial № $436 / 77$

\begin{tabular}{|c|c|}
\hline \multicolumn{2}{|c|}{ Nombre coloquial: Archivo Judicial. } \\
\hline Clasificación & $\begin{array}{l}\text { Fondo Documental; Expediente Judicial № } 436 / 77 \text { “Biblioteca Vigil s/ } \\
\text { Operaciones de Liquidación". }\end{array}$ \\
\hline $\begin{array}{l}\text { Contexto de } \\
\text { origen }\end{array}$ & Tribunales Provinciales de Rosario. Juzgado Civil y Comercial $14^{\circ}$ nominación. \\
\hline Localización & $\begin{array}{l}\text { “Asamblea de Socios por la Recuperación de la Biblioteca Popular Constancio C. } \\
\text { Vigil”. Asesores legales. Dr. Marcelo Abaca y Dr. Marcelo Scalona. }\end{array}$ \\
\hline $\begin{array}{l}\text { Tiempo de } \\
\text { exploración }\end{array}$ & $2007-2012$ \\
\hline $\begin{array}{l}\text { Contenido } \\
\text { General }\end{array}$ & $\begin{array}{l}\text { VIII Cuerpos. Proceso judicial iniciado en abril de } 1977 \text { tras la declaración de } \\
\text { quiebra patrimonial por parte de Comisión Interventora. En términos generales: } \\
\text { demandas de particulares por retrasos en la entrega de premios; inventarios de } \\
\text { bienes muebles e inmuebles; tasaciones, ventas, subastas y remates (actas, } \\
\text { edictos y recibos); nóminas de acreedores (empresas, particulares, organismos } \\
\text { del Estado); notas recibidas/enviadas entre actores (numerosas y por diversas } \\
\text { temáticas desde 1977-1983); mandamientos; informes técnicos de diversas } \\
\text { oficinas burocráticas (Rentas, servicios públicos, etc.); solicitudes y respuestas } \\
\text { sobre verificación de créditos; rendiciones de cuentas de bienes liquidados; } \\
\text { honorarios interventores; distribución de utilidades. }\end{array}$ \\
\hline
\end{tabular}


16

acceso a esta documentación resultó posible tras las previas gestiones realizadas por la denominada "Asamblea de Socios por la Recuperación de la Biblioteca Popular Constancio. C. Vigil"20, dado que el control sobre el estado de la causa judicial y estadio de la liquidación patrimonial de la entidad constituyó una de las primeras acciones por ellos realizadas. Específicamente, dos asesores legales miembros de la Asamblea y ex alumnos del Instituto Secundario, se abocaron a la búsqueda y análisis del expediente judicial 436/77 en el año 2004. Por entonces aquello no resultó sencillo, pues el corpus judicial no lograba ser ubicado en su debido lugar; esto es, en los Tribunales Provinciales de Rosario (Juzgado Civil y Comercial, $14^{\circ}$ Nominación). Ulteriormente, se conoció que la totalidad de la documentación vigente (1977-2004) se encontraba en el domicilio particular del interventor Dr. Emilio Echen en funciones desde los años dictatoriales. Desde ya, lo dicho constituyó la primera irregularidad de un largo listado que pudo corroborarse una vez estudiado el expediente. Entre los aspectos más destacables cabe citar: gobernador de facto, los correspondientes órganos de control nunca fueron notificados (Fiscalía de Estado e Inspección de Personas Jurídicas); así como no se le dio participación a los síndicos de la entidad según lo determinaba el estatuto de la organización; situación que prosiguió durante la posterior etapa liquidadora y tras el reinicio a la vida constitucional hasta el año $2004^{21}$, incumpliendo con la obligación de informar (al menos) trimestralmente el estado de la liquidación a los órganos competentes declarados en la normativa en cuestión. Claro que ello resulta algo más que un mero incumplimiento normativo, por cuanto el delito que porta toda la carga histórica del período dictatorial se anuda a la imposibilidad del estatutario control por parte de los dirigentes institucionales en rigor de la renuncia coactiva, detención ilegal y desaparición forzada de los fiscalizadores. Como se deslizó páginas arriba, estas acciones fueron condición de posibilidad de los delitos económicos cometidos. Sobre esta dimensión, el archivo judicial permite visibilizar y probar el nudo del caso: en tanto las deudas originadas por la actividad de la entidad mutual no llegaron a U\$S 100.000, por su parte, el patrimonio ascendía aproximadamente a U\$S 3.500.000, los cuales “desaparecieron" sin control a lo largo de 31 años de ininterrumpida liquidación ${ }^{22}$, destacándose un total de U\$S 700.000 en honorarios cobrados por los civiles liquidadores Guillermo Tasada (1977-1979) y Dr. Emilio Echen (1979-2004) y asesores intervinientes. Cuando explicitamos que este expediente judicial resulta una confesión de partes, para este punto en particular, ello se patentiza en la foja 785 con fecha 6 de septiembre de 1979; allí el liquidador declara:

“[...] Existiendo eventualmente la posibilidad de que el producido de la liquidación de los bienes que componen el activo exceda el importe de los créditos verificados y a verificar, gastos de la liquidación y todos los otros rubros que serán oportunamente discriminados mediante rendición de cuentas, solicito, salvo el mejor criterio de S.S., se aplique sobre el eventual remanente las disposiciones establecidas por la ley 21.488 [Ley Quiebras y Concursos. Ajustes de créditos]."

Vale decir, "la posibilidad eventual", es posibilidad cierta. La instancia de un monto que exceda todo lo adeudado y/o gastado, es un cálculo contable previsible e inequívoco. Si las deudas eran menores al líquido patrimonial, y si, no obstante ello, una cifra millonaria se hizo a costa de subastas y remates (en muchos casos viciados) de valiosos bienes muebles e inmuebles, sin más, el proceso resultó un saqueo devastador de carácter imprescriptible. 

efectivizadas por los liquidadores en autos. Sin entrar aquí en datos distractores, cabe mencionar que en dicha materia el expediente está poblado de sugerentes ausencias documentales, así como rendiciones de pagos y/o depósitos parciales y/o fuera de término, que nuevamente atestiguan el nulo control del proceso. Lo novedoso en el caso (aunque no inédito en la historia) resulta el curioso fundamento brindado por el interventor Dr. Emilio Echen. En foja 496 con fecha 9 de febrero de 1999, el liquidador informa al tribunal que "personas desconocidas habrían ingresado a las dependencias del 'Camping Vigil' (Centro Recreativo, Cultural, Social y Deportivo 'La Colonia') ubicado en la ciudad de Villa Gobernador Gálvez en el mes de diciembre de 1998 y sustraído documentación". Al acompañar la denuncia policial del hecho, no detalla sin embargo los documentos robados sino que hace una descripción genérica. Desde ya, el detalle del faltante resulta sustancial en estos episodios por la gravedad que inviste y considerando que el denunciante era depositario de bienes ajenos sujetos a su administración. económicos utilizados por la intervención para distribuir los créditos verificados, es decir, el total de los montos específicos de acreedores demandantes en autos (se trate de premios adeudados, indemnizaciones laborales y/o deudas fiscales), pocas dudas quedan respecto de una operación arbitraria e infundada. Lo dicho se sustenta observando la ausencia de todo criterio matemático y financiero para determinar lo anterior. Asimismo, se constata un grave daño al proceso en los proyectos de distribución efectivizados (reparto de los ingresos por liquidación patrimonial) tras la venta de los bienes más importantes de Biblioteca Vigil. Principalmente, se observa la equívoca aplicación de la Ley 21.488, norma vigente para los concursos y quiebras civiles, pero que ciertamente no se contempla para el caso de la ley de Mutuales 20.331 que corresponde a la persona jurídica Biblioteca Vigil. Ley, por su parte, que sirviera al gobernador de facto para intervenir una normalización. En suma, los supuestos remanentes de los millonarios ingresos que dejan la ventas edilicias y muebles, se distribuyeron entre los acreedores según la clasificación que estipula la ley de quiebras, beneficiando en primera instancia a los llamados "Acreedores con Privilegio General"; en segunda instancia, a los "Acreedores Quirografarios", y por último, a los "Acreedores por deudas laborales". Para el último caso, los montos resultan insignificantes e injustificados, ya que no surge del expediente el criterio utilizado para determinarlos. Vale decir, los únicos privilegiados fueron entonces los acreedores que portaban deudas fiscales con la entidad. Así, todo queda saldado en la esfera del Estado provincial y nacional; claro está, en la esfera de un Estado terrorista.

21

Irregularidades en el procedimiento. Bienes y fondos. Al respecto se observa la no correlación de fechas y fojas del expediente, así como la ausencia de informes generales de los créditos supuestamente verificados. Esto es, el paso procedimental básico para una distribución efectiva de indemnizaciones según la normativa que técnicamente clasifica a la masa de acreedores; deudas posibles de ser saldadas tras las subastas y remates de bienes de alto valor monetario realizados durante el año 1979. Precisamente, 1979 bien puede calificarse como el año "de las grandes liquidaciones" en el caso, atendiendo a la subasta de siete inmuebles practicadas los días 12 y 19 de septiembre. Tras estas operaciones, la intervención se alza con un monto total de $\$ 30.115 .000$, pero solo se verifica el depósito de $\$ 19.231 .000$. Ciertamente, este robo cobra mayor dimensión cuando se consideran los magros depósitos solicitados por los asociados a la Caja de

Corpus, Vol 3, No 2 | 2013 
Ayuda Mutua, cerrada en la primera semana normalizadora. Hasta donde fue posible saber, nunca le fueron repuestos sus ahorros.

Pero todo lo descripto hasta aquí todavía no constituye el desfalco más notable operado en esta liquidación: la venta de los bienes edilicios que componían la gran esquina de las calles Alem y Gaboto del sur rosarino, inmueble donde se asentaran las escuelas formales e informales (Universidad Popular). A saber, con fecha 21 de mayo de 1980 (fs. 1124/25), el Tribunal autoriza la venta por la suma de $\$ 4.184 .000 .000$, equivalente a U\$S 2.500.000, sin que obre en autos constancia de la operación (escrituras públicas, constancia de ingreso de la suma de dinero a la masa liquidable y/o instrumento público que perfeccione esa transferencia). Y cabe enfatizar, transferencia en la cual el Estado provincial es parte compradora y vendedora simultáneamente. Esta particular transacción no resultó sencilla para el régimen; al parecer, el botín más preciado comportaba una serie de estorbos políticos, sociales y educativos inéditos en relación al desguace hasta entonces perpetrado y a considerar especialmente en la historiografía educativa. En principio, el día 8 de noviembre de 1979, el Dr. Tasada remite una nota al juez de la causa explicando que el inmueble en cuestión:

"[...] ocupa un lugar especialísimo [...] que puede dividirse en tres partes: biblioteca, colegio secundario y unidad administrativa. Son tres estructuras distintas, pero que se encuentran íntimamente ligadas entre sí no solamente por la intercomunicación existente, sino también porque no aparece una delimitación clara entre las mismas, a punto tal que subsuelos, maquinarias y otras instalaciones son comunes." (Expediente judicial "Biblioteca Popular Constancio C. Vigil. Operaciones de liquidación" Cuerpo IV, foja 1075).

A continuación agrega:

"[...] la enajenación de dicho inmueble plantea un serio problema pues dado su superficie y características el mercado comprador es reducidísimo. Como factor incidental, debe tenerse en cuenta que su ubicación no resulta la más adecuada por estar relativamente alejado del sector céntrico de la ciudad." (fs. 1075)

Puede saberse también que la derivación de los inmuebles (y con ello las escuelas curriculares de la esfera provincial) no resultó la primera opción intervencionista. El Dr. Tasada continúa entonces:

"Preocupación constante de la intervención ha sido la de encontrar un comprador para dicho inmueble. A fines del año 1977 se había despertado el interés de la COMISION NACIONAL DE INVESTIGACIONES ESPACIALES, ante la cual se llevaron a cabo distintas tramitaciones con el objeto de poder concretar su venta.[...]Pero pese a las tratativas realizadas, que comprendieron entrevistas con el BRIGADIER SÁNCHEZ PEÑA tanto en esta ciudad como en la Capital Federal, y al hecho de que el ente estatal estudió los planos de los inmuebles que le fueron facilitados por esta intervención, sin haber formulado observación al respecto, la COMISION NACIONAL DE INVESTIGACIONES ESPACIALES, al cabo de un lapso bastante prolongado, hizo saber que no tenía ya interés en concretar la operación. Tal circunstancia resulta lamentable no sólo por la circunstancia apuntada en el párrafo anterior, sino también por los esfuerzos y el tiempo empleados. Se han realizado distintas gestiones a diferentes niveles sin que las mismas hayan fructificado hasta el presente." (fs. 1075).

En suma, los otrora valores socioculturales y pedagógicos de Biblioteca Vigil se tornan disvalores para las ansias liquidatorias, ya fuere por la interconexión de espacios edilicios que materializaban la articulación educativa, o, al decir de un ex alumno, las características de un edificio "pedagógicamente inteligente", o dada la lejanía con el centro de la urbe que dificulta encontrar un comprador interesado en un 
emprendimiento circundado por el estigmatizado ${ }^{23}$ barrio "Tablada"; dato que ciertamente disminuye sensiblemente el precio de tasación según lo dejan ver otros escritos agregados en autos. En este contexto, hace su aparición el Ministerio de Educación de la Provincia de Santa Fe.

"No obstante, es de destacar que a raíz de una gestión directa de la intervención ante el Sr. Ministro de Educación de la Provincia de Santa Fe, se despertó el interés de dicho funcionario por el complejo educacional, a punto tal que lo ha visitado a fin de tomar un conocimiento directo del edificio, ha requerido los planos pertinentes y solicitado informes técnicos relativos al inmueble, su construcción, posibles falencias, y factibilidad de su terminación." (fs.1076).

Efectivamente, la Nota № 478 firmada por el gobernador Vicealmirante Jorge Desimoni dirigida al Dr. Tasada el día 15 de febrero de 1980, explicita:

"[...] Entiendo que sería una sana política reactivar el complejo educativo cultural de referencia por cuanto su creación dejó en la ciudad de Rosario esperanzadas expectativas sobre la sa... [Ilegible] acción de aspectos indispensables en lo educativo y cultural en una zona tan populosa y en continua expansión. En la acción de reorganización nacional en que hemos comprometido nuestros esfuerzos no puede suprimirse aquello que se inició para servir a la educación y a la cultura, aunque posteriormente haya sido utilizado con fines opuestos a nuestra unidad nacional. Por el contrario es nuestro deber reactivarlo y adecuarlo a un uso correcto y racional conforme a los objetivos de su creación. Por todo ello es nuestra intención continuar y mejorar aun los servicios que prestan la Escuela Primaria, la Escuela Secundaria y la Biblioteca, adecuando dichos servicios con las condiciones y características propias de la administración provincial. En [ilegible] posteriores se incrementará la prestación de otros servicios que hacen al ámbito de actuación del Ministerio de Educación y Cultura." (fs.1102-1103).

Para tamaña operación, el Teniente Coronel Héctor Hiram Vila, Interventor del Instituto Nacional de Acción Mutual (I.N.A.M.) no formula reparo "para la prosecución de las acciones tendientes a concretar la venta de los inmuebles [...] especialmente considerando, que se asegura la continuidad de los distintos establecimientos educativos y de la biblioteca". Se acepta entonces el (supuesto) plan de pagos ofrecido por el Gobierno Provincial y se señala la conveniencia de "dar celeridad a los trámites necesarios para la firma de los documentos correspondientes". Cumpliendo con la celeridad sugerida por el militar, el Dr. Tasada informa las buenas nuevas al juez de la causa a fines de marzo de 1980, efectivizándose el 21 de mayo del mismo año. Algunos meses después, el día 13 de septiembre de 1981, el proyecto se presenta en sociedad con la "inauguración" del flamante "Complejo Pedro de Vega". Aquel día, el ministro de educación Eduardo Sutter Schneider, explicitará:

"La idea de un complejo educativo y cultural en la ciudad de Rosario hace más de dos décadas fue plasmada con la creación de la hoy ex - Biblioteca Constancio C. Vigil. El gobierno de la Provincia, consciente de que una de las principales tareas de este Proceso es la de reordenar valores, entendió como conveniente rescatar para esta ciudad y especialmente para una zona tan populosa como la que nos rodea un proyecto cultural y educativo de gran envergadura que había sido confundido en el tiempo por ideas y motivaciones políticas opuestas a nuestro ser nacional." ${ }^{24}$

Ahora bien, como es sabido, uno de los elementos más visibles de la Política Educativa Procesista (Kaufmann, 2006) se inscribe en el viraje hacia el principio de subsidiariedad del Estado en la prestación de los servicios educativos, bajo la doble modalidad del retraimiento financiero-administrativo y la ampliación, aliento e intensificación de terceros coeducadores en las figuras (neo) tradicionales de los agentes naturales: Iglesia 
católica y familia nuclear. Aunque no pretendemos profundizar en ello ahora, este es el rasgo histórico educativo en el cual se enmarca la "salvaguarda" del Estado provincial respecto de las arrasadas escuelas. En este sentido, y ya por fuera del fraude en la compraventa de los inmuebles, resulta significativo el progresivo y ascendente interés por conservar lo "propiamente escolar" de la institución. Es decir, al tiempo que se eliminan, clausuran, destruyen, prohíben y expulsan objetos, actividades y grupos de trabajo en las diversas dimensiones pedagógicas, científicas, socioculturales y productivas-cooperativas, los interventores, y más aun, el Estado educador subsidiario, promueven y sostienen la continuidad del sistema formal de enseñanza en sus tres niveles. Con ello, cabe inferir que el Estado de facto podía (re)asumir un rol principal según lo apremiara el caso en cuestión y en términos de control, disciplinamiento y moralización de espacios y sujetos. En rigor, antes que un retorno/desvío del orden subsidiario, cabe considerar una centralización, seguimiento y depuración pedagógica-institucional, si atendemos a lo efectivamente realizado más allá del discurso de un proyecto de "reactivación" de un "complejo" educativo adecuado "a un uso correcto y racional" dotado de servicios, e incremento de la prestación de otros no especificados. Ello nunca se efectivizó. Por el contrario, el devenir de los años expuso los profundos efectos de esta operación por cuanto se abandonó todo esfuerzo por sostener su otrora calidad educativa. Durante la década del 80 y todavía más en los años 90, emergió una expresión popular que condensa esta dimensión; por estos años, las escuelas de Biblioteca Vigil tendrán un mote clasista muy particular: si antes los vecinos llamaban a esta escuela con orgullo y dignidad "la Vigil", el Complejo "Pedro de Vega" será nombrado como "la Villil"; una escuela "de villeros" y "para villeros", carente de dispositivos materiales, humanos y simbólicos para torcer la marginalidad que golpea sobre estos sectores sociales.

\section{Archivo Rubén Naranjo: el archivo militante}

Gráfico № 2: Archivo "Rubén Naranjo”

\begin{tabular}{|c|c|}
\hline \multicolumn{2}{|c|}{ Nombre coloquial: Archivo "Rubén Naranjo" } \\
\hline Clasificación & Colección de documentos institucionales pre y post intervención. \\
\hline $\begin{array}{l}\text { Contexto de } \\
\text { origen }\end{array}$ & $\begin{array}{l}\text { Unidad Administrativa; Instituto Secundario; Departamento de Educación; } \\
\text { Escuela de Música (Universidad Popular); Departamento de Publicaciones; } \\
\text { Servicio Bibliotecario; Observatorio astronómico; Caja de Ayuda Mutua; Centro } \\
\text { de Cómputos; Centro Materno-Infantil; Guardería; Departamento de Ciencias } \\
\text { Naturales; Departamento de Construcciones. }\end{array}$ \\
\hline Localización & Domicilio particular de Marina Naranjo (actual custodia del acervo). \\
\hline $\begin{array}{l}\text { Tiempo de } \\
\text { exploración }\end{array}$ & Visitas semanales durante los meses de julio y agosto de 2008. \\
\hline $\begin{array}{l}\text { Contenido } \\
\text { general }\end{array}$ & $\begin{array}{l}\text { Fuentes primarias institucionales pre-intervención (1959/1977): acta } \\
\text { fundacional; estatuto institucional original y modificaciones ulteriores; } \\
\text { reglamentos internos varios; memorias y balances contables; planificaciones } \\
\text { escolares; informes anuales generales y particulares de cada departamento y } \\
\text { sección. }\end{array}$ \\
\hline
\end{tabular}


Fuentes primarias visuales (1957-1976): 170 fotos digitalizadas.

Fuentes primarias institucionales post-intervención (1977): carta de renuncia de la Comisión Directiva; memorándums; notas; decretos y resoluciones de intervención.

Producida la intervención liquidadora, Naranjo resolvió auto exiliarse deambulando por diferentes puntos de la provincia de Buenos Aires habiendo ya constatado el peligro que corría su vida ${ }^{25}$. Desde aquellos años de ausencia, y más aún tras el retorno a la democracia, comenzó a acumular documentos, fotografías y recortes de diarios que en su conjunto construyeron un espacio íntimo que llamó "el estudio". El volumen que este adquirió con los años demandó su propio lugar, por lo cual alquiló una modesta pensión en la cual, bajo una lógica militante, creció un archivo personal catalogado y clasificado en orden de sus preocupaciones; los eternos "temas" de Rubén: la dictadura, los "chicos de la calle", la educación, la impunidad y el abuso del poder policial, la memoria y el arte, la vida y obra del Dr. Janusz Korczak, y desde ya, "La Vigil".

Tras su fallecimiento (2005) este quedó bajo la custodia de su hija Marina Naranjo a quien conociéramos en el marco de la ya mencionada asamblea por la recuperación de Biblioteca Vigil. Explicitados los propósitos de la investigación, en el año 2008 accedimos a las cajas rotuladas "Vigil 1", "Vigil 2", "Vigil 3" con documentos impregnados de sus propios trazos (anotaciones al margen, formas de agrupar y/o dispersar fuentes, escritos a los que le fueron adicionados recortes de hemeroteca, etc.). En parte, las fuentes fueron utilizadas para su trabajo publicado en 1991, en tanto muchas otras, parecían aguardar un uso posterior y diferencial. En particular, resultó decisiva la serie "Memoria Institucional y Balance Contable" 1972-1976. Su análisis permitió delinear con claridad las rupturas y continuidades económicas sobre cada ámbito institucional, hasta entonces presentes como una historia homogénea. De forma pormenorizada, los informes elevados desde cada departamento hicieron posible la reconstrucción del organigrama y periodización del crecimiento exponencial (1965-1973), el impacto de los problemas financieros (1974-1975) y las prioridades definidas frente a la crisis y la instauración de la implacable dictadura (1976). Asimismo, cabe destacar en igual rango de importancia las 170 fotografías digitalizadas. Sin duda, estas fuentes visuales operaron allanando un viaje atemporal para lograr una mejor y justa comprensión de la biografía institucional. Su cognición estética trabajó sobre las propias representaciones, ampliándolas, corrigiéndolas o resignificándolas.

\section{El Archivo de la Federación de Cooperadoras Escolares de Rosario}

Desde el año 1959 y hasta 1977, Augusto Duri fue presidente de la CD de Biblioteca Vigil. Terminada su experiencia y ya entrada la década del 90, el ex dirigente volvió a evidenciar su inquieto espíritu emprendedor en un megaproyecto social y asistencial denominado "La Cocina Centralizada". La misma funcionó entre 1991-1996 en un local de $7.000 \mathrm{~m} 2$ perteneciente a la Federación de Cooperadoras Escolares (FCE) de Rosario. En poco tiempo llegó a producir 32.000 raciones diarias para 180 comedores escolares. 

instalaciones. Llegados a los subsuelos del vasto edificio, dimos con un ecléctico archivo que incluía parte de la historia de la FCE, la mencionada Cocina Centralizada y el llamado Centro de Prestaciones Pedagógicas, integrante también de la Federación.

pocas oportunidades el encuentro de fuentes documentales resulta fortuito, no obstante sucede, y este es el caso. Entre aquellos armarios destartalados reparamos en una pequeña caja de cartón etiquetada con el nombre "Vigil". Esta contenía documentación institucional ya dada por perdida. Inmediatamente se hicieron gestiones para conservar o reproducir estas fuentes. No obstante los breves días que demandaron estos trámites, al ingresar nuevamente al edificio se nos informó que "ya habían sido cargados cuatro camiones de papeles y basura para su destrucción". Gran cantidad de documentos primarios referidos a Biblioteca Vigil fueron parte de aquel desecho continuando la marcha de una historia de censuras, depuraciones y quemas, aunque ahora víctima de la ignorancia y la desidia.

Solo la caja "Vigil" (separada durante la primera visita) quedó a resguardo.

Gráfico Nº 3: Archivo de la Federación de Cooperadoras Escolares de Rosario

\begin{tabular}{|c|c|}
\hline Clasificación & Colección de fuentes institucionales preintervención (1965-1971) \\
\hline $\begin{array}{l}\text { Contexto de } \\
\text { origen }\end{array}$ & $\begin{array}{l}\text { Secretaría (Correspondencias); Departamento de Bonos (Interior y } \\
\text { Delegaciones) }\end{array}$ \\
\hline Localización & Subsuelo local Federación de Cooperadoras Escolares de Rosario. \\
\hline $\begin{array}{l}\text { Tiempo de } \\
\text { exploración }\end{array}$ & Marzo-junio 2010. Visitas semanales. \\
\hline \multirow{4}{*}{$\begin{array}{l}\text { Contenido } \\
\text { general }\end{array}$} & $\begin{array}{l}\text { Cartas y notas de pedidos o agradecimientos para/por donaciones realizadas } \\
\text { por Biblioteca Vigil (materiales, construcción de viviendas económicas, libros, } \\
\text { bibliotecas, etc.) firmadas por docentes, directivos de escuelas, asociaciones } \\
\text { civiles, jefes comunales e intendentes de localidades pequeñas en distintas } \\
\text { provincias de Argentina, 1970-1971. Total: } 23\end{array}$ \\
\hline & $\begin{array}{l}\text { Carta del ex presidente Juan Domingo Perón a dirigentes de Biblioteca Vigil en } \\
1971 .\end{array}$ \\
\hline & $\begin{array}{l}\text { Resoluciones, decretos y ordenanzas provenientes de diversas oficinas } \\
\text { burocráticas ubicadas en Santa Fe, Córdoba, Buenos Aires y Salta que autorizan } \\
\text { ventas de rifas de la entidad en su jurisdicción o eximen del pago de impuestos } \\
\text { en razón de funcionar como asociación civil sin fines de lucro, 1965-1971. Total: } \\
20 \text {. }\end{array}$ \\
\hline & $\begin{array}{l}\text { Cartas y notas de funcionarios oficiales en altos cargos gubernamentales } \\
\text { nacionales y provinciales que gestionaron la eximición de impuestos sobre los } \\
\text { bonos de Biblioteca Vigil a favor de la entidad, 1968-1969. Total: } 5 \text {. }\end{array}$ \\
\hline
\end{tabular}


aspectos caben destacarse de las fuentes "rescatadas". Por un lado, se constataron obras benéficas de la entidad en diferentes puntos del país, manifiesto en decenas de cartas escritas por docentes y directivos de escuelas ubicadas en pequeñas y lejanas localidades del país; principalmente, son muestras de agradecimiento fraterno por libros donados y/o ayuda monetaria. En una mirada más amplia, también permitieron constatar los modos de funcionamiento institucional en cuanto al tejido de relaciones comunitarias por fuera de su radio local y provincial, coincidiendo en este sentido con las descripciones que dejaran las entrevistas realizadas.

Otras fuentes desnudaron empíricamente un problema harto evidenciado en los testimonios de los ex directivos de la entidad: la ardua tramitación político-burocrática para obtener la eximición de impuestos sobre las emblemáticas rifas. Específicamente, se dio con un conjunto de epístolas que evidenciarían unas prácticas lobistas a favor de la organización, operada por altos y reconocidos funcionarios militares (provinciales y nacionales) durante los años 1968-1969; por ejemplo:

Imagen $\mathrm{N}^{\circ} 1$ : Documentación hallada en el Archivo Federación de Cooperadoras Escolares.

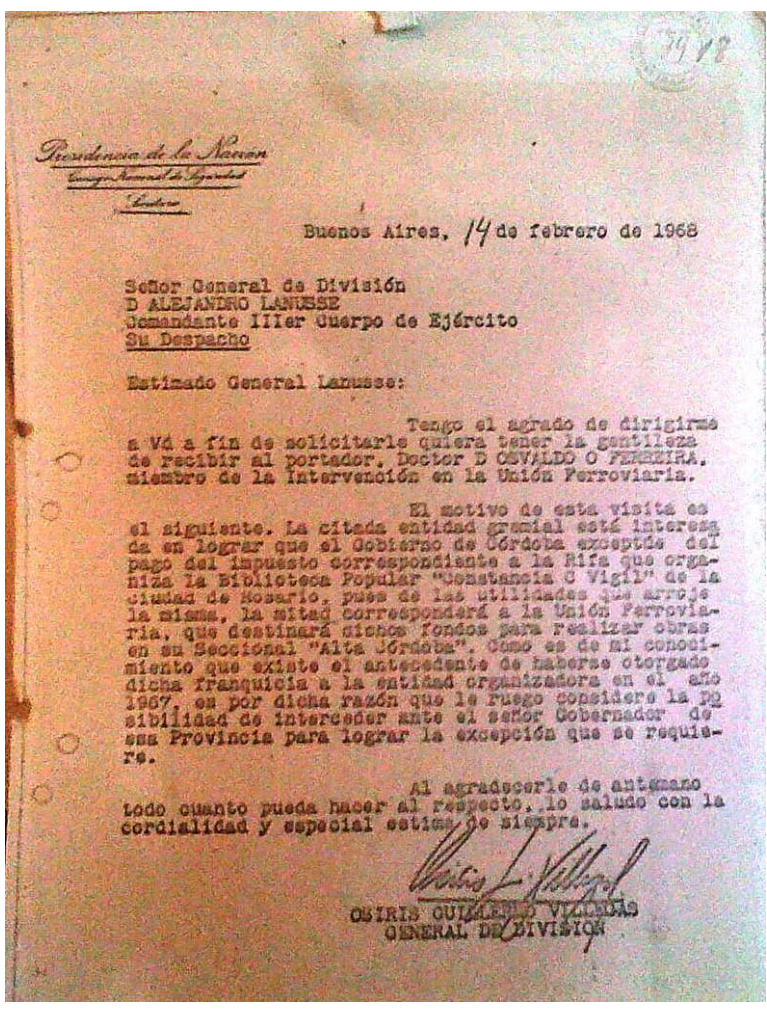

Al respecto, los testimonios explicitaron someramente la existencia de "gestiones" a cargo de legisladores provinciales representantes de las principales fuerzas partidarias y funcionarios civiles o militares durante los gobiernos autoritarios. En este último caso, por un lado, las memorias describen una serie de conflictos y debates de orden éticopolítico al interior de la $\mathrm{CD}$, al tiempo que enfáticamente niegan toda posibilidad de privilegio material o simbólico a cambio de dichas mediaciones.

Estas y otras fuentes permitieron tensionar la novela institucional caracterizada por un relato apolítico y virtuoso que omite sus propios conflictos e intereses populares. La mediación del General Osiris Villegas en el año 1969, particularmente repudiado en los testimonios, embiste contra el imaginario de una institución-isla, "prístina", alejada e 
incontaminada por la mundana arena política. Desde ya, este escenario igualmente demarca los límites infranqueables entre los períodos autoritarios anteriores (1966-1973) y el terrorismo de Estado implantado desde 1976. Desde entonces, al menos para "la Vigil", ya nada resulta negociable o evitable en virtud de un influyente intermediario.

\section{La biblioteca personal del Prof. Mario López Dabat: un archivo exiliado} prolífica biblioteca personal a diferentes instituciones de la ciudad de Rosario. Así, toda la bibliografía de orden pedagógico fue llevada a la Escuela de Ciencias de la Educación de la Facultad de Humanidades y Artes (UNR) a finales del año 2008. Allí comenzó entonces nuestra búsqueda.

Gráfico № 4: Biblioteca "Prof. Mario López Dabat"

\begin{tabular}{|c|c|}
\hline \multicolumn{2}{|c|}{ Nombre coloquial: Biblioteca "Prof. Mario López Dabat" } \\
\hline Clasificación & Colección de fuentes institucionales-pedagógicas preintervención (1972). \\
\hline $\begin{array}{l}\text { Contexto de } \\
\text { origen }\end{array}$ & $\begin{array}{l}\text { Departamento de Educación y Cultura de la Biblioteca Popular "Constancio } \\
\text { C. Vigil", Instituto Secundario. }\end{array}$ \\
\hline Localización & $\begin{array}{l}\text { Escuela de Ciencias de la Educación. Facultad de Humanidades y Artes. } \\
\text { Universidad Nacional de Rosario. }\end{array}$ \\
\hline $\begin{array}{l}\text { Tiempo de } \\
\text { exploración }\end{array}$ & Abril, mayo, junio y julio de 2010. \\
\hline \multirow{6}{*}{$\begin{array}{l}\text { Contenido } \\
\text { general }\end{array}$} & Ficha "tipo" evaluación de profesores del Instituto Secundario, s/f. \\
\hline & $\begin{array}{l}\text { Comunicaciones del Departamento de Educación a directivos de las escuelas } \\
\text { de todos los niveles de la institución y Universidad Popular, s/f. }\end{array}$ \\
\hline & Nota de Prof. Antonia Frutos a Prof. Mario López Dabat, 1974. \\
\hline & $\begin{array}{l}\text { Ficha "tipo" visita domiciliaria. Guardería, escuela primaria y jardín de } \\
\text { infantes, s/f. }\end{array}$ \\
\hline & $\begin{array}{l}\text { Calificación del personal docente. Documento del Sistema Nacional de } \\
\text { Enseñanza Privada. }\end{array}$ \\
\hline & $\begin{array}{l}\text { Reglamento de calificación del personal de los establecimientos de } \\
\text { educación primaria. }\end{array}$ \\
\hline
\end{tabular}




\begin{tabular}{l}
$\begin{array}{l}\text { Curso intensivo para formar directores de curso. Asignaturas: “Evaluación } \\
\text { escolar"; "Técnicas de Estudio", "Estudio Dirigido". } 1972\end{array}$ \\
\hline Estudio Dirigido: plan general; plan de trabajo; cuadros; informe general. \\
\hline $\begin{array}{l}\text { Directores de curso: objetivos general de la tarea; curso intensivo; } \\
\text { asignatura: "Planificación de las tareas escolares". }\end{array}$ \\
\hline $\begin{array}{l}\text { Evaluación, observaciones y calificación de trabajos prácticos para Curso } \\
\text { Directores de Curso, por parte del Prof. López Dabat. }\end{array}$ \\
\hline Recortes de diarios del CONSUDEC (Consejo Superior de Educación Católica) \\
\hline
\end{tabular}

41 Las fuentes "exiladas" resultaron inestimables para ahondar en las tramas políticoeducativas y didáctico-curriculares harto promocionadas desde la memoria de los actores institucionales, pero escasamente seguidos con rigurosidad documental en investigaciones académicas. En particular, el corpus hallado habilitó unos análisis pormenorizados de los singulares dispositivos pedagógicos incorporados a la cotidianeidad escolar del Instituto Secundario entre los años 1970-1977; a saber: el denominado "Sistema de Directores de Curso" y los programas de "Estudio Dirigido", "Orientación Vocacional” y "Orientación Emocional". En particular, el Estudio Dirigido dejó ver la potente influencia de las corrientes psicológicas de la educación ciertamente preocupadas (y así significadas en el espacio escolar) por los correctivos conductuales grupales e individuales; las prevenciones al fracaso escolar; la motivación subjetiva del estudio y la sistemática apropiación de los conocimientos por vía de unas técnicas pautadas y capilarmente verificadas. No obstante, se observó también una relativización de su impronta (meramente) técnico-eficientista con el rol de los directores de curso, por cuanto su cercana presencia restituía a la relación educativa algo de su intrínseca complejidad antropológica y sociológica. Sintéticamente, los documentos guardados por el pedagogo permitieron comprender que el frente predilecto de batalla institucional para alcanzar una democratización popular en el reparto del conocimiento, se anudó a unos objetivos antienciclopedistas y antidogmáticos. Ambos fueron institucionalmente leídos en clave de un dominio laicista y construcción del conocimiento bajo un espíritu científico. Aun cuando en términos estrictos no puede hablarse de positivismo per se, lo cierto es que una "guía positivista" orientó gran parte del proyecto educativo de la escuela media. Mejor dicho, su amplia y compleja trama epistemológica fue recortada y resignificada por los intereses y objetivos de la cultura institucional para volverla una herramienta eficaz contra la alienación de los dogmas teológicos y como matriz didáctica metodológica.

Tal análisis se destaca aquí como un develamiento del archivo, que sacude un discurso pedagógico que en ello sólo ve tradición vetusta, conservadurismo, tecnocracia e incluso autoritarismo, y que sin embargo (posiblemente) sería menos cuestionado si se tratara de la formación de las capas medias y altas. Sin intenciones de irnos hacia tan complejo debate, significamos entonces que la documentada impronta positivista embiste contra una larga representación institucional patentizada en algunos antecedentes y todavía más en la divulgación oral. Este corpus en particular habilitó dilucidar que Biblioteca Vigil no intentó ser vanguardia política ni experiencia radicalizada orientada a un orden disruptor como se ha sugerido; por el contrario, la orientación dominante fue la 
complementariedad, el suplemento, el aditamento y el apuntalamiento. Fue audaz en términos de su cultura material per se y al disponerla sobre el campo popular. El rol aduanero de su cultura institucional dejó pasar la técnica organizacional y puso reparos a las tendencias rupturistas de las corrientes pedagógicas que deambulaban fuera e intramuros, aspirando a la apertura de nuevos mundos cognitivos en el barrio "Tablada", sin olvido de los legítimos intereses de sus habitantes, por momentos reñidos con los enclaves que suponían la "mejor educación" fuera o dentro del campo escolar.

Dicho lo anterior, nuevamente cabe hablar de una novela institucional-pedagógica que no pudo/deseó describir esta experiencia sino como baluarte local y señera de la implementación de teorías críticas y "alternativas". Enfatizamos entonces que nos ha resultado muy interesante advertir que "ese positivismo" operó como la donación política más fecunda para un empoderamiento real de los sectores populares alcanzados. En torno de este núcleo duro, sí orbitó un subgrupo de postulados y tendencias que amanecían desde la psicogénesis, las últimas oleadas del escolanovismo, las lecciones freireanas ${ }^{27} \mathrm{o}$ la tensión de comulgar con las teorías reproductivistas en el plano de la superestructura y, no obstante, apostar por la transformación social en la topología escolar. Ello fue vehiculizado en las sienes y en la piel de las trayectorias y perspectivas de algunos docentes y directivos, que vieron/creyeron/sintieron allí un lugar "diferente" y posible para ponerlas en acción. Sin embargo, las fuentes orales y más aún documentales analizadas habilitan señalar estas influencias en un rango secundario. Así, el progresismo pedagógico se significó como igualdad de rigurosidad cognitiva sin subestimaciones confundidas en un significante infértil de "lo alternativo". Lo alternativo fue comprendido como inédito material complementario, parasistemático y supletorio no rupturista. Exponer lo representado-supletorio por sobre lo nodal-documentado habla antes bien de una incomodidad epistemológica y disciplinaria.

\section{5. “La Vigil” en el Archivo Provincial de la Memoria (Santa Fe)}

El Archivo Provincial de la Memoria está ubicado en la ciudad capital de Santa Fe. Siguiendo a Jelin (2002), su acervo es fiel producto del accionar burocrático dejado por una cadena de mandos y responsabilidades entre las diversas instituciones clandestinas y represivas que operaron en el territorio provincial; un conjunto de fondos documentales que muestra todos los vicios de la "cultura del informe policial o de inteligencia" (p. 5). Cronológicamente, sus huellas datan desde 1966 y hasta 1983. Estas fuentes, clasificadas de orden "estrictamente confidencial y secreto", fueron localizadas en el año 1987. Dos años después, se aprobó la conservación permanente de todos sus documentos. En 1995, la gobernación provincial dispuso su traslado al Archivo General de la Provincia. Finalmente, desde mediados del año 2009, permanece en préstamo y custodia en el Archivo Provincial de la Memoria (Ministerio de Justicia y Derechos Humanos) a los efectos de ser debidamente catalogado, clasificado y digitalizado.

Ahora bien, al momento de iniciar esta investigación, se desconocía este sinuoso devenir; más aún, se ignoraba su existencia. Y resulta curioso que las referencias nos llegaran por la prensa escrita bajo el título "Huellas policiales del terrorismo de Estado. Encontraron el archivo de Inteligencia de la policía santafecina de la época de la última dictadura" ${ }^{28}$. Especialmente, atrapó nuestra atención su denominación periodística "Los archivos ideológicos [por cuanto] contienen esencialmente información de inteligencia sobre militantes políticos, gremiales y sociales [...] y entidades intermedias, clubes y 
asociaciones civiles". Pero un llamado telefónico a la Secretaria de Derechos Humanos refutó la imagen de un "hallazgo" inesperado; sin disimular las molestias y tensiones ocasionadas tras la publicación mediática, el anónimo funcionario explicitó "algunos periodistas ignoran que desde hace muchísimos años trabajamos con estos archivos". Ciertamente, no solo se trataba (y trata aún) de este sector social, pues en ocasión del II Encuentro Regional de Archivos y Derechos Humanos, Águila ya había expresado "En esta provincia existe un acervo documental bastante poco conocido que se encuentra actualmente localizado en la ciudad de Santa Fe" (2008b, p. 21). Por fuera de estas vicisitudes, y dada la excelente predisposición y colaboración del equipo a cargo, se iniciaron las tramitaciones para acceder al acervo según los requerimientos protocolares y categorías que contempla el organismo. Pudo hallarse:

Gráfico $\mathrm{N}^{\circ}$ 5: Archivo Provincial de la Memoria (Santa Fe)

\begin{tabular}{|c|c|}
\hline \multicolumn{2}{|c|}{ Nombre coloquial: Archivo Provincial de la Memoria (Santa Fe) } \\
\hline Clasificación & Archivo Provincial de la Memoria de la ciudad de Santa Fe. \\
\hline $\begin{array}{l}\text { Contexto de } \\
\text { origen }\end{array}$ & $\begin{array}{l}\text { Fondo Dirección General de Informaciones Provincia de Santa Fe (1976-1983); } \\
\text { Fondo Policía de la Provincia de Santa Fe (1976-1983); Fondo Servicio } \\
\text { Penitenciario de la Policía de Santa Fe (1976-1983) }\end{array}$ \\
\hline Localización & $\begin{array}{l}\text { Sede de la Secretaría de Derechos Humanos, Santa Fe (ciudad capital de la } \\
\text { provincia). }\end{array}$ \\
\hline $\begin{array}{l}\text { Tiempo de } \\
\text { exploración }\end{array}$ & Visitas esporádicas años 2009-2011. Total: 8 \\
\hline \multirow[t]{6}{*}{$\begin{array}{l}\text { Contenido } \\
\text { general }\end{array}$} & $\begin{array}{l}\text { Dirección General de Informaciones. Expediente Antecedentes Constancio C. } \\
\text { Vigil D/Ste. 111/68. Sobre la licitación de la Lotería de la Provincia de Santa Fe. }\end{array}$ \\
\hline & $\begin{array}{l}\text { Dirección General de Informaciones. Serie Ficha de personas. Año } 1971 . \\
\text { Profesor del Instituto Secundario "Constancio C. Vigil". }\end{array}$ \\
\hline & $\begin{array}{l}\text { Dirección General de Informaciones. Serie Ficha de personas. Año } 1972 . \\
\text { Profesor del Instituto Secundario "Constancio C. Vigil". }\end{array}$ \\
\hline & $\begin{array}{l}\text { Dirección General de Informaciones. Serie Ficha de personas. Año } 1973 . \\
\text { Profesor del Instituto Secundario "Constancio C. Vigil". }\end{array}$ \\
\hline & $\begin{array}{l}\text { Dirección General de Informaciones. Serie Ficha de personas. Fechado } \\
\text { 09/08/1968. Adjunta nómina de Comisión Directiva de Biblioteca "Constancio } \\
\text { C. Vigil" solicitada por S.I.D.E. (Secretaría de Inteligencia de Estado) }\end{array}$ \\
\hline & $\begin{array}{l}\text { Fondo Policía de la Provincia. Sección “Partes policiales". Bibliorato № } 48 \text {. } \\
\text { Memorándum № } 2.774 \text {. Fechado 11/04/1975. Atentado explosivo en la } \\
\text { Biblioteca Vigil. }\end{array}$ \\
\hline
\end{tabular}




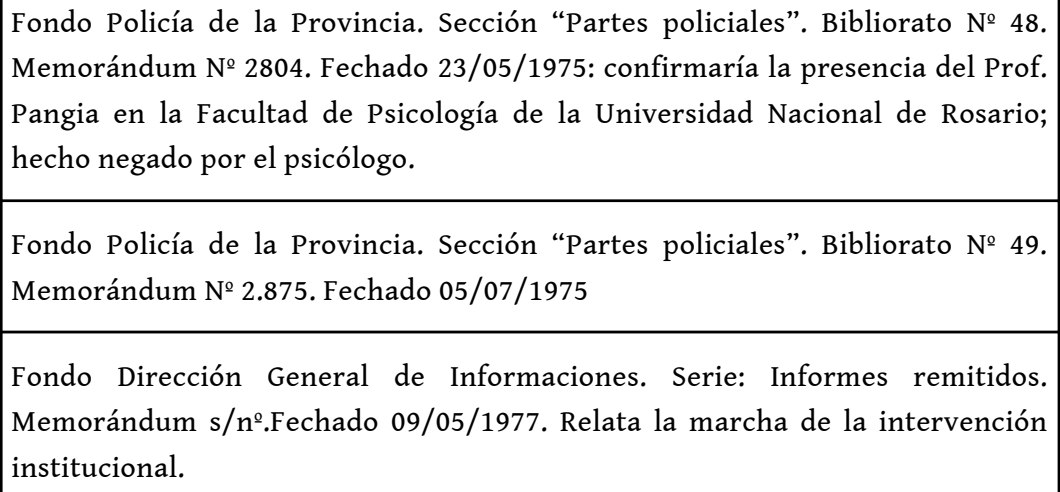

En primer lugar, la burocracia del terror permitió precisar delimitaciones temporales que las memorias no retienen en torno de la violencia política que alcanzó a la entidad durante los años 1975 y 1976; esto es, fechar y profundizar datos clave que los olvidos apenas rozan en torno de los atentados, intromisiones diurnas y nocturnas y amenazas sufridas en aquellos años. De forma más fecunda, el mencionado archivo habilitó visibilizar lo sabido-invisible: la persecución ideológica y tareas de inteligencia sobre la persona jurídica Biblioteca Vigil, principales actores institucionales y colaboradores del campo artístico, literario y universitario. En otras palabras, específicos documentos ratificaron lo expresado en variados testimonios y bajo expresiones tales como: "La Vigil fue intervenida por razones ideológicas", "los problemas económicos fueron una excusa", "esto venía desde mucho antes". Pero, ¿desde cuándo exactamente? Pues, desde el convulsionado año 1968 y en torno de un hecho específico: la licitación de la Lotería de la Provincia de Santa Fe; un acontecimiento en verdad complejo de describir en todas sus dimensiones pero que puede resumirse como un evidente cercenamiento del poder político y económico local que llega hasta el gobernador de facto Eladio Vázquez (1966-1970). Dicho cercenamiento se orientó por entonces al crecimiento económico exponencial y continuo de "la Vigil". Esto es, tras ganar la mencionada licitación y habiendo presentado la mejor oferta técnica, patrimonial, impositiva y social según lo reconocen los propios informes secretos y confidenciales, subrepticiamente se decretó (№ 4.610/68) desierta la compulsa hasta, finalmente, establecer un cambio en la Ley de Contabilidad provincial al año siguiente que dejó fuera de competencia a la Biblioteca Vigil. Desde entonces se excluirá del concurso a entidades de bien público pudiendo solo licitar empresas comerciales que a la fecha dividen monopólicamente al territorio en dos concesionarios. En dicho contexto, y mediando numerosas trabas burocráticas, el gobierno provincial envió decenas de inspectores de la entonces Dirección General Impositiva que requisaron la organización en largas jornadas. Aquello fue interpretado como un punto de inflexión que no llegó a devenir en una interrupción institucional; la memoria de aquella primera intervención o intervención "blanda" y limitada, hoy resulta relativizada por la brutalidad de la "verdadera" y definitiva intervención de 1977.

Por fuera de estas significaciones, la visita de los inspectores veló la búsqueda de documentación "comprometedora" respecto de una infiltración del comunismo internacional; lo cierto es que paralelamente Biblioteca Vigil resultó "fichada" en los servicios de inteligencia local, provincial y nacional, acumulando desde entonces cuantiosos y detallados informes. 
Imagen $\mathrm{N}^{\circ}$ 2: Envío datos personales de la Comisión Directiva de Biblioteca "Constancio C. Vigil" a solicitud de SIDE (Secretaría de Inteligencia de Estado) y recabada por la Dirección General de Informaciones en 1968. En Fondo Dirección de Informaciones. Bibliorato 371. Archivo Provincial de la Memoria, Santa Fe.

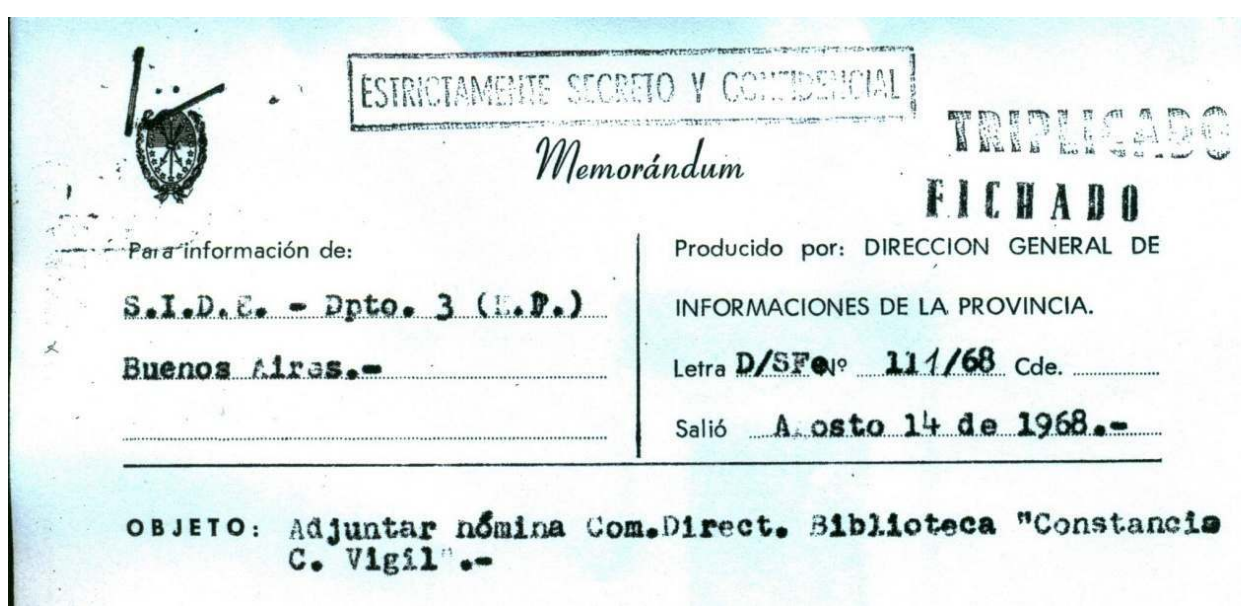

Con relación a lo último, se registró una significativa diferencia entre el "fichaje" de la entidad por parte de los servicios de inteligencia durante la década del $60 \mathrm{y}$ aquellos de los primeros 70. Las inéditas fuentes documentales encontradas en el Archivo Provincial de la Memoria (Santa Fe) indicaron que la "peligrosidad" institucional trasuntó desde la advertencia y presencia de actores (principales o secundarios) sobre los cuales pesaba una serie de antecedentes ideológicos, a un rango donde ella misma resultó el componente "a registrar". En términos sencillos, hasta 1974-1975 "la Vigil" era "fichada" por la cercanía de militantes, artistas, pedagogos o directivos procedentes de las filas marxistas o socialistas. En adelante, algunos actores institucionales fueron "fichados" por "ser de la Vigil". Por citar un solo ejemplo y entre otro casos similares, la "ficha personal" del profesor Edgardo Ossanna (Instituto Secundario) enumera entre sus "peligrosos antecedentes": "docente de la escuela secundaria de la Biblioteca Vigil: centro de actividad marxista" ${ }^{29}$, verificándose incluso que la fecha de tal registro es el año 1972; esto es, en pleno auge económico-financiero de la entidad liquidada.

Imagen $N^{\circ}$ 3. "Antecedentes" del Prof. Edgardo Ossanna. Ficha Fondo Dirección de Informaciones. Caja 493. Legajo 1. Archivo Provincial de la Memoria, Santa Fe.
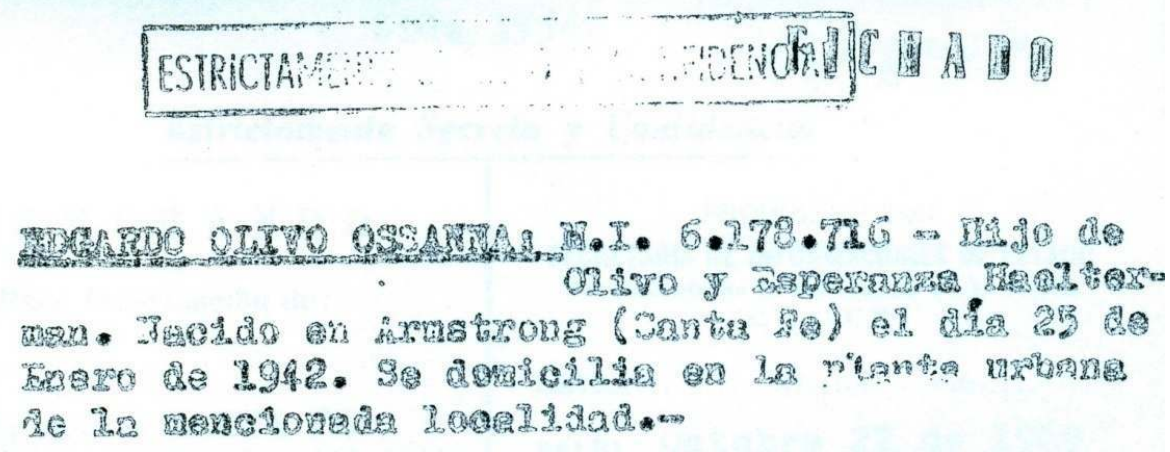

Corpus, Vol 3, No 2 | 2013 


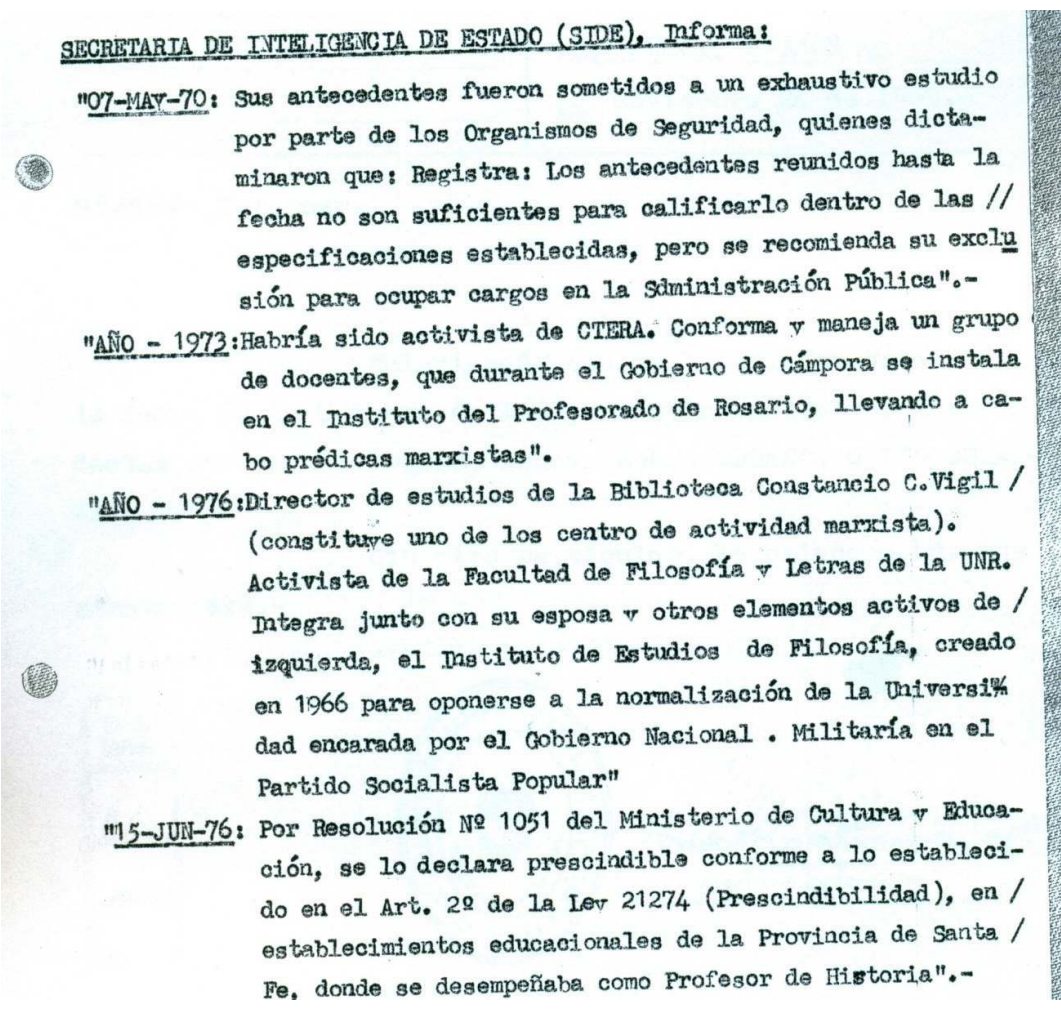
en el archivo personal de Rubén Naranjo refutan la inevitable aplicación de una quiebra patrimonial, estos documentos clandestinos abonan la hipótesis de una intervención política-ideológica largamente pergeñada.

\section{El archivo escolar. el menos oculto de los ¿archivos ocultos?}

El retorno a la vida democrática no produjo efecto benéfico alguno al interior del ex Instituto Secundario de Biblioteca Vigil desde su periodo intervencionista. Bajo una misma cadena de olvidos e impunidades, y hasta bien entrada la década del 90 , continuaron en funciones directivos y docentes convocados durante la etapa dictatorial. Aun cuando desde 1981 el establecimiento ya era parte de la órbita estatal, el núcleo duro que administró la vida escolar no ingresó o renovó sus cargos por las vías institucionales correspondientes (escalafón oficial). Tal es el caso de la directora Prof. Vilma Donadío, registrada en las fuentes documentales antes y después de la creación del "Complejo Pedro de Vega" ${ }^{30}$ y en cargos directivos desde mediados de los años 90.

51 Hacia el ciclo lectivo 2003, los escándalos de corrupción y malversación de fondos sobre su figura colmaron la paciencia de un grupo de padres y cooperadores de la escuela secundaria. Las pruebas reunidas en su contra culminaron en una denuncia penal que finalmente encontró eco en el Ministerio de Educación (Santa Fe). Tras un largo sumario administrativo, Donadío fue depuesta de su cargo en el año 2008. En su lugar, asumió una docente de la etapa pre intervencionista: Prof. América Libertad Finamori.

Se interpreta que tal recambio resultó clave para la búsqueda de documentación primaria de estricto orden escolar. Tras una breve gestión, la flamante directora permitió entonces hurgar en espacios que se aventuraban con fuentes del período; en rigor, la docente expresó que desconocía el devenir del material solicitado, si acaso aún existía, e interpuso

Corpus, Vol 3, No 2 | 2013 
una condición a nuestro pedido: "Que sea para contar la verdad, lo que realmente pasó"... aún reflexionamos sobre el sentido preciso de su demanda.

Las fuentes documentales primarias emergieron en distintos ámbitos de la escuela: en armarios olvidados pero ubicados en la oficina de Dirección; en un cuarto en desuso del $2^{\circ}$ piso $\mathrm{y}$, de forma mayoritaria, en un depósito del $6^{\circ}$ piso. Ciertamente, el volumen y calidad del archivo escolar, permitió recortar el objeto de estudio en el Instituto Secundario para un análisis topográfico del proceso intervencionista. En suma:

Gráfico N ${ }^{\circ}$ 6: Archivo de la escuela secundaria $\mathrm{N}^{\circ} 338$ "Constancio C. Vigil"

\begin{tabular}{|c|c|}
\hline \multicolumn{2}{|c|}{ Nombre coloquial: Archivo Escuela Secundaria } \\
\hline Clasificación & $\begin{array}{l}\text { Fondo Documental (1970-1983): } \\
\text { fuentes primarias institucionales pre } \\
\text { y post intervención. }\end{array}$ \\
\hline Procedencia institucional & $\begin{array}{l}\text { Departamento de Educación y } \\
\text { Cultura de Biblioteca Popular } \\
\text { "Constancio C. Vigil", Instituto } \\
\text { Secundario. }\end{array}$ \\
\hline Localización & $\begin{array}{l}\text { Dirección (oficina) actual Escuela № } \\
338 \text { ( } 2^{\circ} \text { piso); Depósito abandonado } 6^{\circ} \\
\text { piso. }\end{array}$ \\
\hline Tiempo de exploración & $\begin{array}{l}\text { Visitas semanales durante los meses } \\
\text { de septiembre y octubre de } 2008 \text {. }\end{array}$ \\
\hline Contenido & $2^{\circ}$ piso \\
\hline \multicolumn{2}{|c|}{$\begin{array}{l}\text { Bibliorato "Supervisiones años } 1981 \text { al 1984": contiene } 23 \text { actas y } 32 \text { notas de supervisores de } \\
\text { Sistema Nacional de Enseñanza Privada (SNEP). }\end{array}$} \\
\hline \multicolumn{2}{|c|}{$\begin{array}{l}\text { Bibliorato “1979 / } 1987 \text { Disposiciones - Ley Reg. Incomp.": decretos, resoluciones, reglamentos, } \\
\text { disposiciones, notas e instrucciones del Poder Ejecutivo provincial y SNEP. Total documentos: } \\
20 .\end{array}$} \\
\hline \multicolumn{2}{|c|}{$\begin{array}{l}\text { Bibliorato "Circulares" (1978-1983): listados de libros prohibidos; ley de "prescindibilidad" } \\
\text { docente; disposiciones generales para el nivel medio y especiales por el Instituto Secundario de } \\
\text { Biblioteca Vigil. Otros que no revisten el carácter de "circulares": nuevos contenidos del ciclo } \\
\text { básico; indicaciones para calificar al personal docente titular, interino o reemplazante al curso } \\
\text { lectivo; Concurso Armada Argentina; entre otros. Total circulares: 28; otros: } 5 \text {. }\end{array}$} \\
\hline \multicolumn{2}{|c|}{$\begin{array}{l}\text { Cuaderno de Actas de los departamentos: Lengua y Literatura (1981-1983), total } 23 \text { actas } \\
\text { Estética y Plástica (1981-1982), total: } 9 \text { actas; Ciencias Sociales: Geografía, Historia, Instrucción } \\
\text { Cívica, Formación Moral y Cívica (1981-1983), total actas: 22; Ciencias Jurídicas: Derechos y } \\
\text { Contabilidad (1981-1983), total actas: 22;Idiomas Extranjeros: Inglés y Francés (1981-1983), tota } \\
\text { actas: } 28 .\end{array}$} \\
\hline
\end{tabular}


Bibliorato "PE año 1982": asignación de cargos 1982; movimientos y nómina del personal; notas intrainstitucionales; planillas de iniciación de clases, horarios del personal, distribución horaria semanal, horas cátedras; plan decreto 4839/80 (Ciclo Básico Único); plan decreto no 6680/56 (Perito Mercantil); Plan decreto 2855/81 (Bachiller Modalizado con Especialidad / Terminalidad) plan decreto 2855/81; plan decreto $n^{\circ}$ 0363/80 (Bachillerato con Orientación Docente). Total documentos: 112.

“Cuaderno de comunicación de novedades mensuales del personal interino” (1981/1982):altas y bajas del personal interino (planillas mensuales). Total documentos: 76.

Bibliorato "Disposiciones y resoluciones de Dirección": disposiciones internas 1982-1983. Total: 7.

Bibliorato "Resoluciones" 1979/1982-1983: total 29 resoluciones y notas; se destaca Resolución № 43/1982. Establece las pautas organizativas para el gobierno del Complejo Educativo y Cultural "Don Pedro de Vega" de la ciudad de Rosario; su comité de gestión y reglamento orgánico.

Bibliorato s/n: circulares, decretos y disposiciones años salteados $(1979 ; 1981 ; 1983)$. Total: 30.

Bibliorato "Inventario": (1981-1983): 5 notas intrainstitucionales; inventario de bienes existentes (51 hojas), cartas entre directivos motivadas por actos probados de sustracción y destrucción de objetos escolares.

Documentos curriculares del Ministerio de Educación y Cultura (1980-1982): cambio de planes de estudio, resoluciones, programas, anexos, etc. Total documentos: 23.

$6^{\circ}$ piso

Acta de exámenes (equivalencias, regulares, previos, libres): 1971-1983.

Legajos de alumnos (datos personales, apercibimientos, informes y evaluaciones): 1970-1983.

Legajos docentes (ficha del personal, hoja de concepto con calificación numérica según "general, profesional y técnica" y "laboriosidad y espíritu de colaboración"; notas de "llamados de atención" del rector del instituto; currículum presentado por el aspirante; certificado de estudios; certificado médico; ley 20.515 Declaración Jurada; régimen de incompatibilidades; informes de observaciones de clase; disposiciones por renuncia/despido, licencias, designación de horas; informes institucionales; solicitud de licencia.

Cabe mencionar que cada documento "hallado" resultó una verdadera sorpresa para los presentes. En tanto el nuevo equipo directivo expresó, simultáneamente, estupor y alegría, los administrativos con más años en sus cargos explicitaron no saber que "eso estaba allí". Efectivamente, a pocos metros de sus escritorios, pudo darse con un libro de Actas titulado "Comisión Cooperadora 1977-1980". En una rápida lectura, se destacaban los nombres de probados genocidas y colaboradores civiles que actuaron durante la intervención de la escuela, tal y como lo habían testimoniado las fuentes orales.

Uno de los documentos más impactantes fue ubicado en el depósito del 6to piso del edificio; una verdadera montaña de papeles desordenados en pésimo estado de 
preservación que solo dejó espacio para el ejercicio de un "justiciero ordenamiento" (Nazar, 2006/2007, p. 214) ${ }^{31}$.

Imagen $\mathrm{N}^{\circ}$ 4: Parte del Archivo Escuela Secundaria (6to. Piso) año 2008.

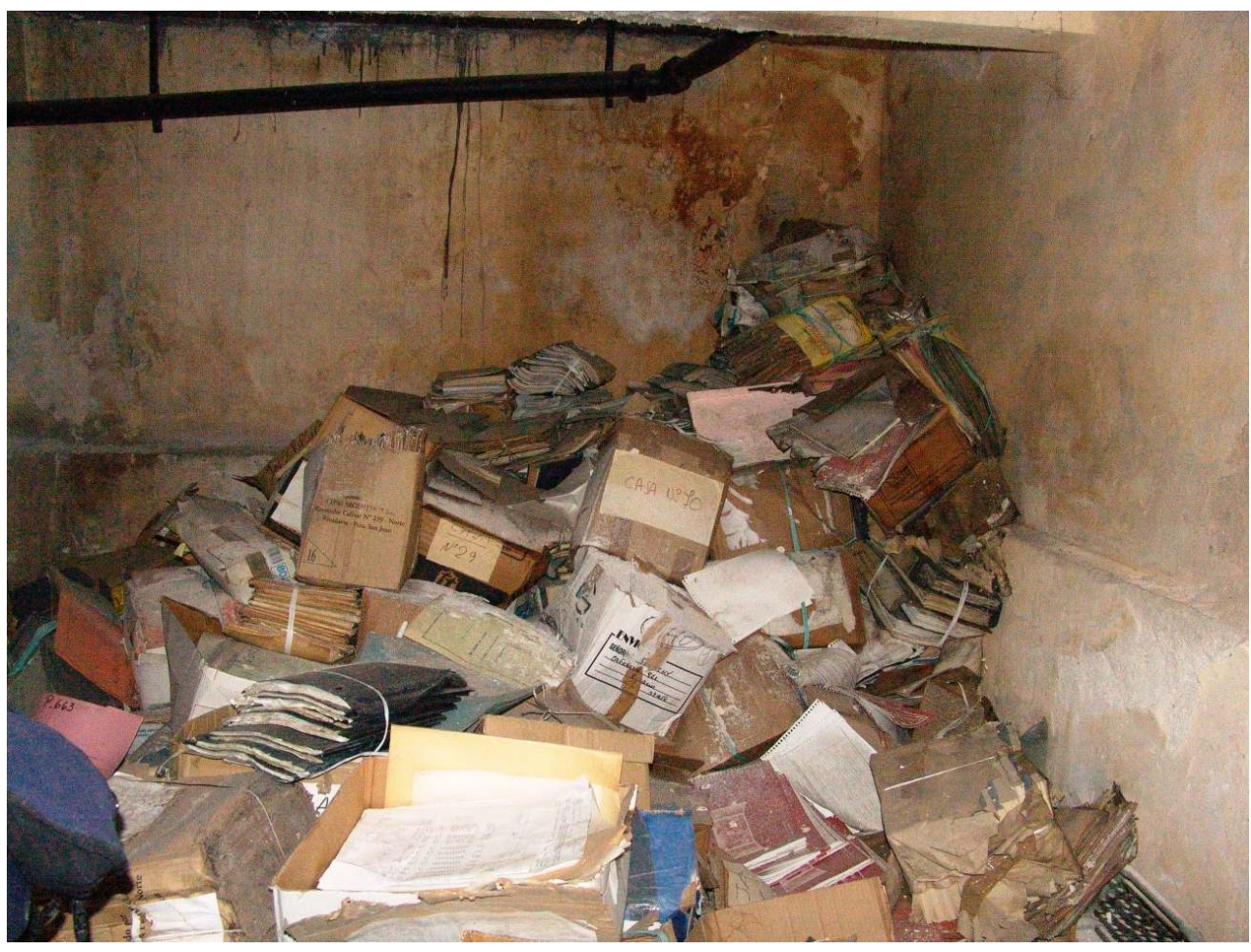

Imagen $N^{\circ}$ 5: Parte del Archivo Escuela Secundaria (6to. Piso). La imagen corresponde al año 2011 tras el traslado desde salón inundado.

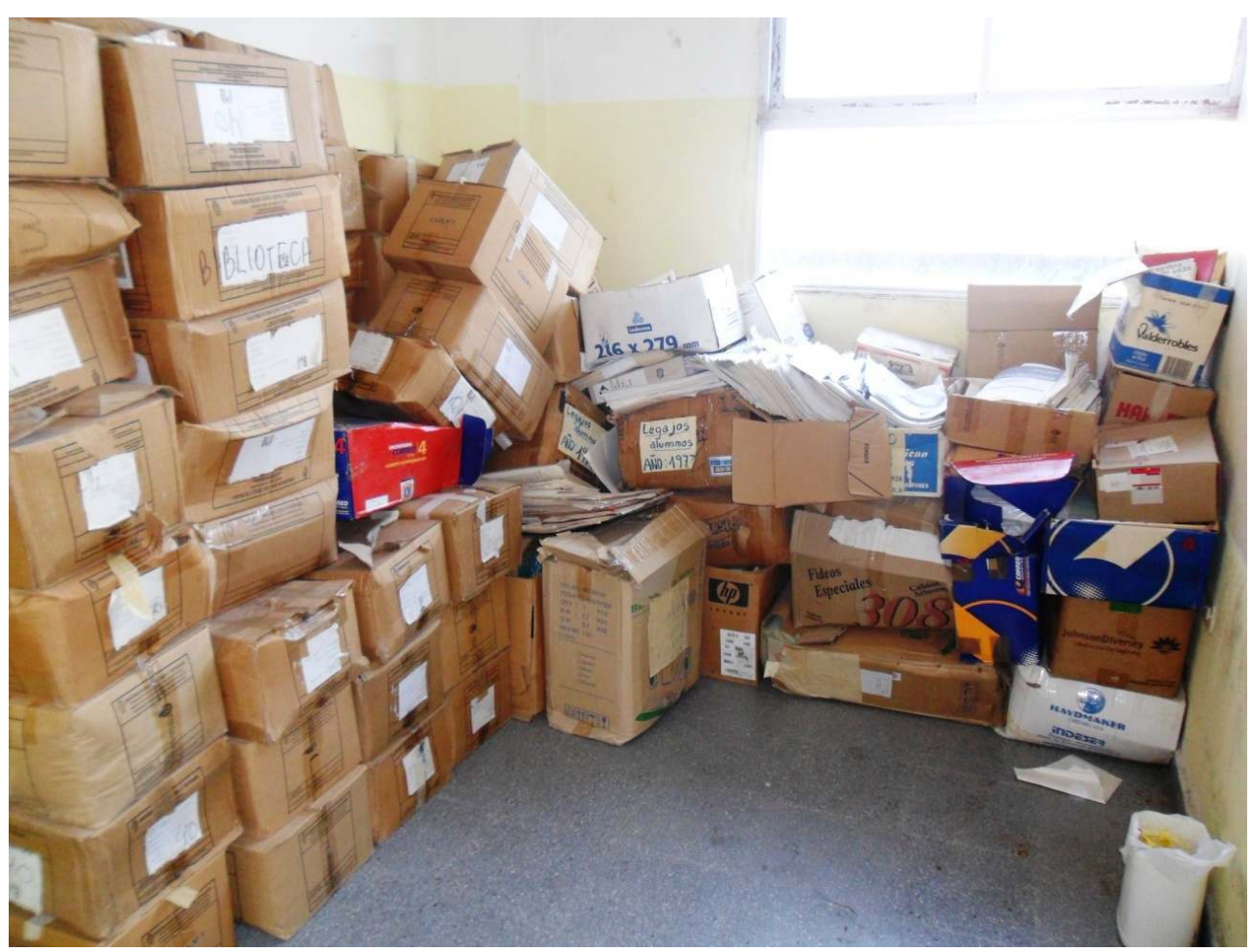

Corpus, Vol 3, No 2 | 2013 
56 Bajo esta lógica dimos con el legajo de la exalumna Celia M. Díaz (DNI 13.692.029) quien a la fecha se encuentra desaparecida. Entre sus folios se destacan dos notas:

Imagen $\mathrm{N}^{\circ} 6$. Pedido del Juez a Directora del ex Instituto Secundario.

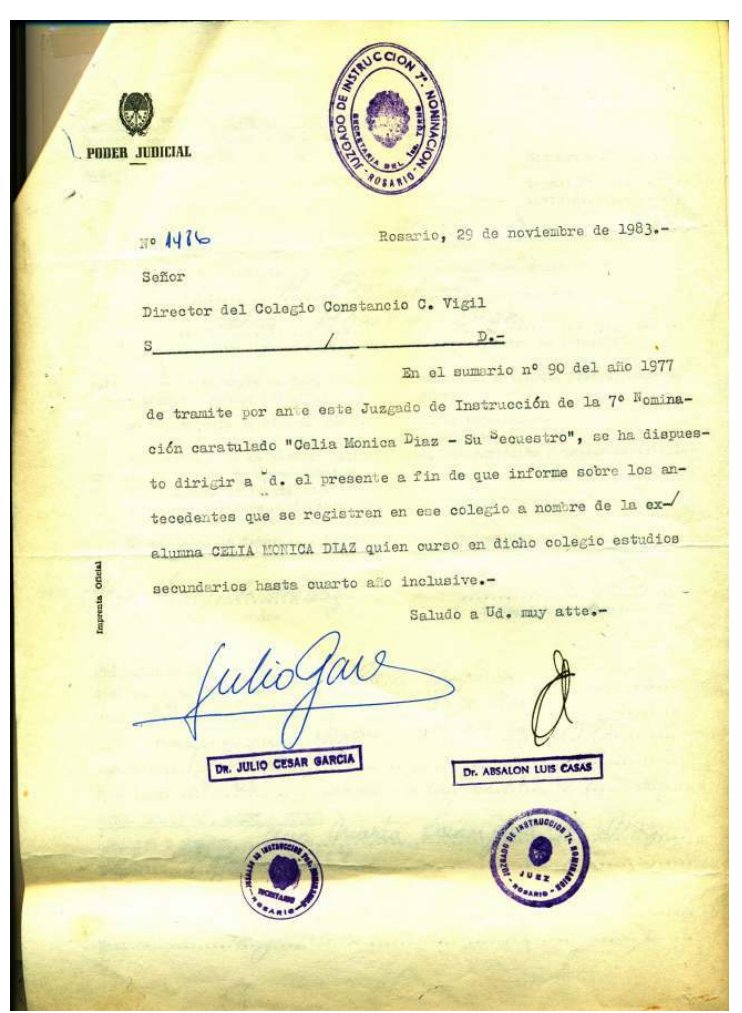


Imagen $\mathrm{N}^{\circ} 7$. Respuesta de la directora al Juez.

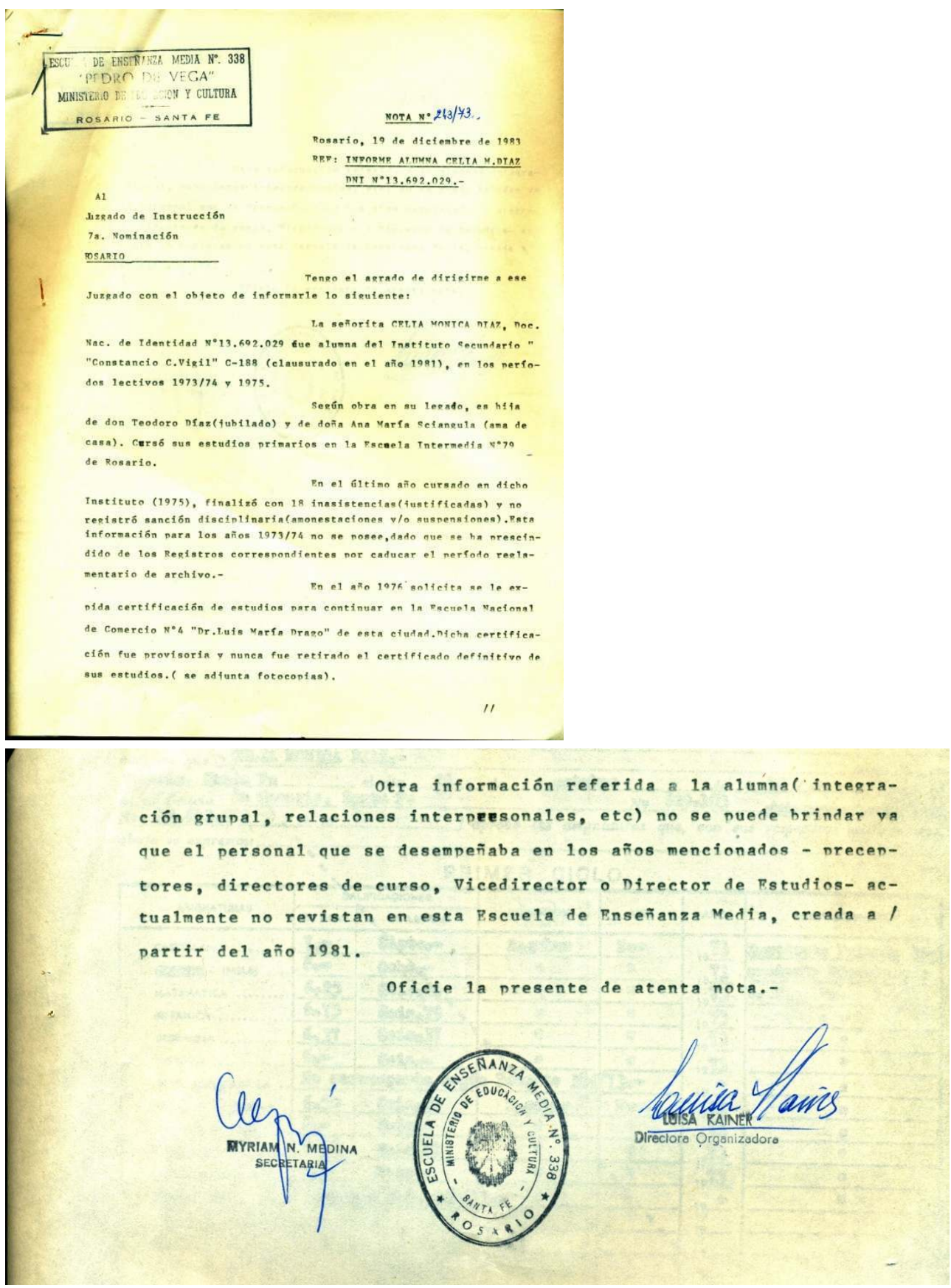

Cabe destacar que el tecnicismo utilizado por la directora y religiosa franciscana Luisa Kainer $^{32}$ en funciones desde mayo de 1983, opera negando todo el escenario donde efectivamente sí pueden ubicarse y suministrarse los datos requeridos por el juez en cuanto a "integración grupal" y/o "relaciones interpersonales", y a modo de reconstrucción del cotidiano escolar de la víctima. De forma más grave, la directora falsea la imposibilidad de dar con actores institucionales contemporáneos a los años escolares de la alumna Díaz y para la fecha asentada. Siguiendo el documento denominado "Nómina de personal elevado a supervisión Zona 1 con fecha toma de posesión", se constata la presencia de al menos siete docentes y una preceptora en condiciones de brindar mayores datos al juez. Quizá cabe aquí considerar la perspectiva de Luisa Kainer en aquellos años 
dictatoriales expresada en una disertación que diera en la Escuela Normal Superior "Rafael Obligado" (San Nicolás, Buenos Aires) el día 26 de mayo de 1976, documento que, curiosamente, se halla en su propio legajo docente; a saber:

“i1976! Año de múltiples facetas y acontecimientos para el pueblo argentino; año en que está vivenciando fuertemente principios claves para la vida nacional [...] Será año de reflexión para aportar orientaciones, evocación de virtudes profundamente humanas con dimensión trascendente, nunca tan oportunas, como hoy, para recordarlas y hacerlas carne en la vida diaria."

Por fuera de los posicionamientos individuales o sectoriales, se interpreta que, si hasta aquí la supervivencia del archivo de la escuela media colmado de documentación clave pre y post intervención institucional podía atribuirse a la mera lógica burocrática escolar, las notas destacadas también avanzan y admiten otras interpretaciones cercanas al orden de la impunidad.

\section{Reflexiones finales}

En muy pocas oportunidades podemos atisbar escenas y escenarios desde los cuales se reconocen, encuentran y construyen las fuentes documentales de una investigación académica. Existe cierto pacto implícito en lo que refiere al abordaje y tratamiento metodológico de las fuentes orales que ciertamente deja fuera a los documentos escritos. Vale decir, en tanto la recuperación de las voces del pasado(y más aún de los pasados traumáticos) interferidas desde el presente, o "función preformativa" de la memoria (Vezzetti,1998), despiertan múltiples ansiedades disciplinarias, por su parte, los acervos impresos y "palpables" suelen presentarse como un apéndice detallado que invisibiliza las condiciones en las que se cuecen los datos más significativos del proceso de indagación. Así, circunstancias clave para la producción del conocimiento son transmitidas de forma dispersa e informal; quizás, en una charla íntima entre conferencista y oyentes, mediante discusiones de pasillo o intercambios de "buena fe" entre colegas.

No por ello se ha pretendido proponer una disminución de la rigurosidad que requiere la historia oral y adosar un anecdotario a cada documento. Tampoco se buscó ingresar al complejo debate de las tensiones historiográficas entre unas y otras fuentes, sino reflexionar sobre los resabios positivistas que rodean la asimetría expuesta; si se prefiere, repensar los acervos en tanto "objeto de análisis no desmembrado de la indagación" (Da Silva Catela, 2002, p. 217).

61 Respecto del caso analizado, dicha articulación comenzó a tejerse acoplada al dato de partida ya señalado: el imaginario popular (pero también el supuesto académico) sobre la destrucción de gran parte de las pruebas de institucionalidad, sino acaso todas. Si por el contrario, a poco de andar en la búsqueda "estéril", se tropezó con significativos archivos que propiciaron fértiles avances para una mejor compresión de la organización antes, durante y después de la intervención cívico-militar, dos efectos tomaron su lugar.

El primero fue de orden epistemológico e interno al proceso de investigación; a saber: al tiempo que las fuentes fueron identificadas, se disparó la falsa idea de un "hallazgo" accidental y afortunado que en rigor enmascara cierta creencia topológica de verdad/ realidad histórica. En otras palabras, "ir hacia" los archivos, permanecer, hurgar y registrar, se constituyeron en composiciones de lugar que no solo cosificaban un recorte historiográfico, sino que abonaban a un convencimiento neurótico de hallar "lo realmente sucedido"; los fondos documentales, así fetichizados, suponían el develamiento 
de las "esencias" furtivas del objeto. Para este plano, salvar la desarticulación advertida por Da Silva Catela (2002), requirió reconocer que eran vestigios de un estallido institucional, pues tales "hallazgos" eran relaciones desanudadas de unas condiciones políticas archivísticas precisas: exilio, contrabando, persecución, dispersión, privatización y pérdida. No obstante, en términos generales, los archivos estaban "[...] a la espera de que alguien hurgue [...] para contar una historia o sume una narrativa" (Jelin, 2002, p. 2).

Desde ya, la mencionada fetichización cobró intensidad en torno de las fuentes documentales que integran los llamados "archivos de la represión". Su grandilocuente litografía ("estrictamente confidencial y secreto"), su carácter clandestino y el simple hecho de escarbar biografías ajenas, por momentos desdibujaba el infausto contexto de producción. Este aspecto se revisó continuamente desde un marco conceptual (Da Silva Catela, 2002, 2007; Jelin, 2002; Nazar, 2003, 2006/2007; Petra, 2006/2007; Pittaluga 2006/2007; Arfuch 2007; Di Biasio, 2007; Águila, 2008b) y más aún metodológico, atendiendo al estricto criterio de la búsqueda de datos articulados a las tareas de persecución ideológica sobre la organización, y analizó, en otra dimensión, las representaciones sociales, políticas e ideológicas que la misma despertaba en sectores del poder político-económico durante las décadas del 60 y 70.

El segundo efecto nos vuelve a la pregunta explicitada en la introducción: ¿Por quéaparentemente-el caso se mueve desde el silencio documental a la proliferación de fuentes escritas? En principio se coincide con Arfuch en cuanto a que "vivimos un presente que [...] parece favorable a la ampliación de los horizontes de memoria, a la interrogación política sobre las responsabilidades" $(2007$, p. 10) de cara a una política de archivos sobre el pasado reciente. Ciertamente, ello tendría pertinencia también en cuanto a la producción de nuevos conocimientos; y al decir de Mariño (2006), a las condiciones sociopolíticas para los debates académicos en torno del terrorismo de Estado. Puede incluso hipotetizarse que este tiempo "favorable" se puso de manifiesto en cada una de las gestiones realizadas para la búsqueda de fuentes. La actual efervescencia discursiva en torno el pasado dictatorial en Argentina habría operado como un lobista exitoso para acceder a ellas.

Sin embargo, limitarnos a esta explicación abonaría una mirada un tanto inamovible o donde las piezas se mueven unilateralmente e incluso solo de "arriba hacia abajo", cuando, sabido es, las políticas de la memoria y con ello la conservación, resguardo y accesibilidad de los acervos históricos expresan diferentes y diversas coyunturas y dinámicas socioculturales. Incluso cabe explicitar que, hasta donde se conoce, la mayoría de los archivos descriptos se hallan en iguales condiciones: abandonados en depósitos, desconocidos, no explorados, inconexos o privatizados.

En suma hasta aquí, a excepción del Archivo Provincial de la Memoria específicamente creado para la custodia y administración del acervo clandestino, se interpreta que el auspicioso encuentro y acceso a documentación primaria sobre la devastada "Vigil", resulta un efecto "políticamente correcto" de la revitalización de las memorias y estudios sobre el pasado dictatorial en sus múltiples dimensiones, pero que aún carece de un tratamiento idóneo en cuanto a políticas de archivo. Con ello, el caso habría ingresado en un régimen de visibilidad inestable (posiblemente coyuntural) y no así en otro orientado a su conservación y responsabilidad hermenéutica.

Por último, ¿cuál es el peso específico del periodo dictatorial respecto del supuesto vacío documental? En principio, tal representación desborda nuestra escala de observación. Siguiendo a Águila, esta fuerte y errónea creencia “...no tiene que ver exclusivamente con 
la historia reciente sino con la ausencia de una política de archivos" (2008b, p. 19); o en palabras de Pittaluga, "se trata de la historia de una ausencia; de la supresión del archivo, o de su emigración, o su privatización" (2007, p. 6). Con ello, hemos visto en el caso cuáles emigraciones, privatizaciones, supresiones o "depósitos sin sentido" (Nazar, 2006/2007) han configurado un acervo residual que positivamente responde tanto a la particularidad de la trama dictatorial como al universo de los problemas archivísticos.

Pero a tales configuraciones, se suma otra forma de ausencia: el peso real y singular de la novela institucional, en tanto la saturación de un relato también es silencio de otros tejidos por la historia, las memorias y el componente traumático. En este sentido nos preguntamos, ¿por qué las voces de Naranjo y Frutos hegemonizaron la historia de la entidad? Se interpreta que ello no solo remite a unos supuestos de total destrucción que sedimentan con el genocidio cultural, así como tampoco cabe inferir una pretensión dominante de los autores. La continuidad del relato debe analizarse como un movimiento mecánico y reproductivista basado en un pseudorrespeto por la memoria popular que en última instancia indica una especie de "pacto silencioso" en pos de no quebrar el carácter de víctima de la mítica Biblioteca Vigil. A nuestro entender, ello es constitutivo de una empatía traumática (LaCapra, 2005) que deja en las sombras sus contradicciones, su intrínseca e ineludible politicidad y toda la humanidad que habita el espacio institucional. Iluminar estos recodos de la historia no hizo otra cosa que potenciar la comprensión de las razones dictatoriales; visibilizarlas no nos alejó de la hipótesis central (intervención política, ideológica y pedagógica), sino que nos aproximó a la conflictividad histórica intra-extramuros y micro-macro que encarnan en toda empresa decidida a la transformación social.

En suma, el corpus (re)aparecido no reviste hallazgo alguno en términos de un descubrimiento o invención histórica. El corpus descripto nos habla de unos encuentros materiales y simbólicos; una apuesta de sentido epistemológico demarcado por unas condiciones sociopolíticas singulares; renovadas perspectivas disciplinarias y diálogo sostenido con las memorias fuertes y débiles (Traverso, 2007). Se trata, en palabras de Derrida (1997) de un corpus que "(...) produce, tanto como registra, el acontecimiento" (p. 24).

\section{BIBLIOGRAFÍA}

Águila, G. (2000). El terrorismo de Estado sobre Rosario (1976-1983). En Plá, A. (Coord.), Rosario en la historia. De 1930 a nuestros días (Tomo II, pp.121-221). Rosario: UNR Editora.

Águila, G. (2008a). Dictadura, represión y sociedad en Rosario, 1976/1983. Un estudio sobre la represión y los comportamientos y actitudes sociales en dictadura. Buenos Aires: Prometeo Libros.

Águila, G. (2008b). Los archivos y los documentos sobre violaciones a los DDHH: usos y limitaciones desde la perspectiva de una historiadora". Ponencia presentada en II Encuentro Regional de Archivos y Derechos Humanos, septiembre 25. Rosario, Argentina. 
Alderete A. (2010). Las aulas, los patios: fueron construidos para dignificar al hombre, la dictadura militar les cambió el destino... Revista de la Escuela de Ciencias de la Educación, Año 4 (no. 5), 95-112. Rosario.

Arfuch, L. (2007). Panel de apertura Archivos y derechos humanos: Usos actuales, posibilidades y limitaciones. En II Encuentro Regional de Archivos y Derechos Humanos, septiembre 26. Rosario, Argentina.

Báez, F. (2005). Historia Universal de la destrucción de los libros. De las tablillas sumerias a la guerra de Irak. Buenos Aires: Sudamericana.

Braslavsky, C. (1986). La situación heredada en 1983: apuntes para su diagnóstico. Temas de Psicopedagogía, 2, 34-51. Buenos Aires.

Cerruti, L. (2010). Cultura y dictadura en Rosario 1976/1983. Rosario: Ediciones del Castillo de la Biblioteca Pocho Lepratti.

Da Silva Catela, L. (2002). El mundo de los archivos. En Da Silva Catela, L. y Jelin, E. (Comps.), Los archivos de la represión: Documentos, memoria y verdad (pp. 195-221). Madrid: Siglo XXI.

Da Silva Catela, L. (2007). Etnografía de los archivos de la represión en la Argentina. En Franco, M. y Levín, F. (Comps.), Historia reciente. Perspectivas y desafíos para un campo en construcción (pp. 183-220). Buenos Aires: Paidós.

Derrida, J. (1997). Mal de archivo. Una impresión freudiana. Madrid: Editorial Trotta.

Di Biasio, P. (2007). Tensión entre publicidad y privacidad de datos sensibles:derecho de habeas data. Ponencia presentada en I Encuentro Regional de Archivos y Derechos Humanos, 2 de octubre. Buenos Aires, Argentina.

Feierstein, D. (2007). El genocidio como práctica social. Entre el nazismo y la experiencia argentina. Buenos Aires: Fondo de Cultura Económica.

Fernández, L. (1994). Instituciones Educativas: dinámicas institucionales en situaciones críticas. Buenos Aires: Paidós.

Fernández, S. y Armida, M. (2000). Una ciudad en transición y crisis (1930-1943). En Plá, A. (Coord.), Rosario en la historia. De 1930 a nuestros días (Tomo I, pp. 23-141).Rosario: UNR Editora. Frutos, R. (1997). La Biblioteca Popular C.C. Vigil. Rosario: Ediciones Amsafe.

Frutos, R. y Naranjo, R. (2006). El genocidio blanco. La Editorial Biblioteca, Vigil, Rosario. En Kaufmann, C. (Direc.), Dictadura y Educación, Tomo III Los textos escolares en la historia argentina reciente (pp. 391-427). Buenos Aires: Miño y Dávila.

García, N. (2008). Los contrabandistas de la Vigil. En Solari, T. y Gómez, J.(Comps.), Biblioclastía. Los robos, la represión y sus resistencias en bibliotecas, archivos y museos de Latinoamérica (pp. 107-138). Buenos Aires: Eudeba.

García, N. (2011). La intervención cívico militar sobre la Biblioteca Popular "Constancio C. Vigil” de Rosario (1977-1980). Un caso para analizar las continuidades y desvíos de la política educativa procesista. Anuario de la Sociedad Argentina de Historia de la Educación, 11, 135-158.

García, N. (2012). Una agenda pendiente: delitos culturales y económicos durante la última dictadura militar argentina. El caso “Biblioteca Vigil” de Rosario, Argentina (1977-2011). Revista Información, cultura y sociedad, (26), 41-64.

García, N. (2013). Reseña de tesis doctoral: Historia sociocultural, política y educativa de la Biblioteca Popular "Constancio C. Vigil" de Rosario (1933-1981). Anuario de la Sociedad Argentina de Historia de la Educación, (13), 1-5. 
Jelin, E. (2002). Introducción. Gestión política, gestión administrativa y gestión histórica: ocultamientos y descubrimientos de los archivos de la represión. En Da Silva Catela, L. y Jelin, E. (Comps.), Los archivos de la represión: Documentos, memoria y verdad (pp. 1-14). Madrid: Siglo XXI.

Kaufmann, C. y Doval, D. (1997).Una pedagogía de la renuncia. El perennealismo en la Argentina (1976-1983). Paraná: Cuadernos de la FCE-UNER.

Kaufmann, C. y Doval, D. (1999) [Edición ampliada 2007] Paternalismos Pedagógicos. Las políticas educativas y los libros durante la Dictadura. Rosario: Laborde Editor.

Kaufmann, C. (2001). Dictadura y Educación. Tomo I: Universidades y grupos académicos argentinos (1976 - 1983). Buenos Aires: Miño y Dávila.

Kaufmann, C. (2003). Dictadura y Educación. Tomo II: Depuraciones y vigilancias en las universidades nacionales argentinas (1976 - 1983). Buenos Aires: Miño y Dávila.

Kaufmann, C. (2006). Dictadura y Educación. Tomo III: Los textos escolares en la historia argentina reciente (1976 - 1983). Buenos Aires: Miño y Dávila.

LaCapra, D. (2005). Escribir la historia, escribir el trauma. Buenos Aires: Nueva Visión.

Malla, J. (2006). El barrio Tablada y los orígenes de la Biblioteca Vigil. Rosario: Asociación Vecinal Rosario Sud Este.

Mariño, M. (2006). Las aguas bajan turbias: política y pedagogía en los trabajos de la memoria. En Pineau, P., Mariño, M., Arata, N.y Mercado, B., El principio del fin. Políticas y memorias de la educación en la última dictadura militar (1976-1983) (pp. 119-207). Buenos Aires: Colihue.

Naranjo, R. (1991). Rosario, historias de aquí a la vuelta. La Biblioteca Popular C. C. Vigil. Ediciones de aquí a la vuelta, (16), pp. 1-26.

Nazar, M. (2003). La accesibilidad documental y sus limitaciones legales: los documentos secretos en la Argentina. Ponencia presentada en V Congreso de Archivología del Mercosur, agosto 28. Córdoba, Argentina.

Nazar, M. (2006/2007). El hilo de Ariadna. Políticas de la Memoria, (6/7), 212-218.

Ossanna E., Ascolani A., Moscatelli M. y Pérez A. (1997). Una aproximación a la educación en Santa Fe 1945 a 1983. En Puiggrós, A. (Direc.), Historia de la educación en la Argentina. Tomo VII La educación en las provincias (1945-1985) (pp. 365-428). Buenos Aires: Ed. Galerna.

Petra, A. (2006/2007). Los documentos particulares como fuentes históricas. La experiencia del Cedinci con los fondos de archivo de las izquierdas argentinas. Políticas de la memoria, (6/7), 206-211.

Pittaluga, R. (2006/2007). Notas a la relación entre archivo e historia. Políticas de la memoria, (6/7), 199-205.

Pittaluga, R. (2007). Democratización del archivo y escritura de la historia. Ponencia en I Encuentro Regional de Archivos y Derechos Humanos Archivos y derechos humanos: actualidad y perspectivas. Buenos Aires.

Rodríguez, L.(2012). Civiles y militares en la última dictadura. Funcionarios y políticas educativas en la provincia de Buenos Aires (1976 - 1983). Rosario: Prohistoria Ediciones.

Tavella, A. M. (2007). La Vigil: un caso de identidad institucional regional. En A. M. Tavella, Identidad colectiva: el caso Rosario desde las perspectivas sociológicas y filosóficas (pp. 75-96). Rosario: UNR Editora. 
Tedesco J.C., Braslavsky C. y Carciofi, R. (1983). El Proyecto Educativo Autoritario. Argentina 1976-1982. Buenos Aires: Flacso, Miño y Dávila.

Traverso, E. (2007). Historia y memoria. Notas sobre un debate. En Franco, M. y Levín, F. (Comps.), Historia reciente. Perspectivas y desafíos para un campo en construcción (pp. 67-96).Buenos Aires: Paidós.

Vezzetti, H. (1998). Activismos de la memoria: el escrache. Puntos de Vista, (62), 8-23.

Viano, C. (2000). Una ciudad movilizada (1966-1976). En Plá, A. (Coord.), Rosario en la historia. De 1930 a nuestros días (Tomo II) (pp. 23-120). Rosario: UNR Editora.

\section{NOTAS}

1. Se decidió el recorte de tres grupos institucionales: ex miembros de Comisión Directiva de Biblioteca Vigil, ex docentes y directivos del Instituto Secundario y ex alumnos. Respecto de los dos últimos, se ponderó una selección que atendiera a unas memorias vividas y atravesadas por las etapas pre y post intervencionistas. Lo dicho se instrumentó por vía de entrevistas en profundidad del tipo semiestructuradas realizadas durante los años 2009-2011. Asimismo se efectivizaron otras breves de carácter informal a otros actores institucionales no previstos en el plan original, en razón de la emergencia de datos específicos que resultaron de los testimonios recabados $\mathrm{u}$ otras fuentes documentales. En cuanto a las fuentes documentales secundarias, se siguieron publicaciones periodísticas (diarios La Capital y Democracia de Rosario y El litoral de Santa Fe. Período 1963-1987) y fuentes audiovisuales; a saber: E. Córdoba (1991) La Vigil. Rosario (s/d). G. Dozo (2005) Los hombres de buena voluntad. La historia de la Vigil, 4AD Comunicaciones, Santa Fe. M. Maseroni y M. Lapenna (2005) Rubén Naranjo, tras las huellas de un humanista. Rosario (s/d) De Grupo "Socios Activos de la Biblioteca Vigil" (2008) Interpelación a Pangia; disponible en http://sociosactivosvigil.blogspot.com. N. Font (2010) Existimos: por la recuperación de la Vigil. Concurso "Programa estimulo a la producción audiovisual del Ministerio de Innovación y Cultura de la Provincia de Santa Fe. Disponible en http://vimeo.com/1190298. Véase reseña tesis García (2013).

2. Las primeras referencias escritas sobre la historia de "la Vigil" se registran en los trabajos de dos actores institucionales: Naranjo (1991) y Frutos (1997). Esta bibliografía operó en tres dimensiones para la investigación: en términos formales resultan antecedentes del problema de indagación; por otro lado, se la incorpora a modo de fuentes secundarias; y en términos conceptuales, se la comprende como parte nodal de la novela institucional, no solo en rigor de su escritura testimonial sino por constatarse una saturada reproducción del relato en ulteriores publicaciones académicas y prácticas de divulgación en general. Respecto del campo académico, las publicaciones pueden agruparse entre aquellas que contienen referencias breves y puntuales y otras que abordan un recorte temporal y/o espacial de la entidad, a modo de unidad de análisis y en virtud de unas averiguaciones particulares. En el primer grupo se registran los trabajos: Ossanna y AA.VV. (1997), Fernández y Armida (2000), Águila (2000) y Viano (2000) y el trabajo del bibliotecario Báez (2005). En el segundo grupo, se destaca el libro del historiador rosarino Malla (2006), cuyo estudio está centrado en el surgimiento y primeros años institucionales. En el otro extremo temporal, se halla la investigación sociológica de Tavella (2007) y los trabajos de García $(2008 ; 2012)$. En un recorte sobre las escuelas fundadas por la entidad y siguiendo el examen de sus características curriculares, didácticas, socioculturales y de su cultura material en general, se ubican los artículos de Alderete (2010) y García (2011). Ajustado a un estudio de las políticas educativas y la biblioclastía perpetrada durante el período dictatorial, pueden citarse, por un lado, el capítulo escrito por Naranjo y Frutos (2006) en "El genocidio blanco. La Editorial 
Biblioteca, Vigil, Rosario" (Tomo III Dictadura y Educación. Los textos escolares en la historia argentina reciente, dirigida por Kaufmann), que aquí sí debe diferenciarse de sus respectivas publicaciones anteriores en tanto su densa trama descriptiva se sostiene desde una problematización y análisis histórico más amplio. Por el otro, la 2da. Edición del libro Paternalismos Pedagógicos (1999 [2007]) de Kaufmann y Doval, cuyo último capítulo a cargo de Kaufmann, "Los libros, la Dictadura argentina y el después", reedita las características depuradoras. Finalmente, y en el marco de un análisis del impacto del régimen dictatorial sobre el campo cultural en la ciudad de Rosario y zona de influencia, el historiador Cerruti (2010) incluye en líneas generales el devenir de la Biblioteca Vigil apelando fundamentalmente a los textos de Naranjo (1991) y Frutos (1997).

3. La Universidad Popular comenzó a funcionar en 1964 con diversos cursos de capacitación que finalmente se organizaron en un formato escolar asistémico: Escuela de artes visuales; Escuela de música; Escuela de Astronomía; Escuela de teatro; Expresión creadora infantil; Ajedrez; Idiomas; Mecanografía, Educación física, entre otros. La Caja de Ayuda Mutua (1967) se crea para el otorgamiento de créditos (personales y para vivienda) a sus asociados. De sus utilidades dependían el Centro Materno Infantil para la atención gratuita durante embarazo, parto y puerperio, y la Guardería que recibía a los hijos de los empleados desde los 90 días de nacidos. La Biblioteca Central fue inaugurada en 1963. Su calidad, caudal bibliográfico y servicio bibliotecario representó uno de sus mayores logros. Por su parte, el Museo de Ciencias Naturales era una espacio integrado al Departamento homónimo en vigencia desde 1964 abarcando funciones de investigación a cargo del personal especializado (taxidermistas) y pedagógicas en tanto espacio didáctico para los alumnos de la institución y escuelas de la ciudad y la región. Lo anterior se aplica también al Observatorio astronómico y su imponente lente de telescopio adquirida en la afamada óptica Zeiss de Alemania; se realizaban allí inéditas prácticas de formación e investigación científica y divulgación popular de la Astronomía. Respecto de la Editorial Biblioteca, cabe sintetizarla como una experiencia sin par en el interior del país que abrió sus puertas en 1966. En 10 años se publicaron más de 90 títulos con una tirada superior a los 2.000 .000 de ejemplares, de los cuales un 1.200 .000 se destinó a donaciones a bibliotecas y a los adquirientes de las rifas. Este emprendimiento y sus particulares políticas editoriales descentralizó la producción de libros baratos a favor de la publicación de noveles y autores consagrados del interior del país. Finalmente, el Centro recreativo social y deportivo refiere a un predio de 23 hectáreas sobre el río Paraná adquirido a finales de la década del 60; una obra en verdad faraónica enteramente construida por el Departamento construcciones de la entidad y sus Talleres productivos (herrería, carpintería, automotores, servicios) que abrió la barranca hacia el río por una calle que bajaba a la playa de 400 metros de extensión, al tiempo que fue elevada unos 3,50 metros para escapar a las periódicas crecientes del Paraná.

4. Por un lado, los bonos tuvieron desde entonces una duración de 24 meses o cuotas, posibilitando la previsión presupuestaria para el año en curso y el subsiguiente. Por el otro, y de forma más decisiva, estos comenzaron a venderse en las provincias de San Juan, Mendoza, Córdoba, Entre Ríos, Salta, Buenos Aires, Tucumán, Jujuy y, por supuesto, en la provincia de Santa Fe. Estas modificaciones dieron sus frutos en la recaudación del 11ํㅡㅇ Bono del año 1966: la cifra trepó de los 35.000 a los 90.000 bonos vendidos.

5. Entendido aquí como una complejización teórica, histórica, política, jurídica y sociocultural del genocidio per se y en los términos clásicos definidos por Artículo $2^{\circ}$ Convención para la Prevención y la Sanción del Genocidio. III Asamblea General de las Naciones Unidas (1948): “[...] cualquiera de los actos perpetrados con la intención de destruir, total o parcialmente, a un grupo nacional, étnico, racial o religioso como tal; estos actos comprenden la matanza de miembros del grupo, lesión grave a la integridad física o mental de los miembros del grupo, sometimiento intencional del grupo a condiciones de existencia que hayan de acarrear su destrucción física, total o parcial, medidas destinadas a impedir nacimientos en el seno del grupo, traslado por la fuerza de niños del grupo a otro grupo". Por un lado, tal complejización se anuda a las 
consideraciones aportadas por Feierstein (2007) quien conceptualiza al genocidio como una práctica social integral y compleja centrado en la "construcción, destrucción y reconstrucción de las relaciones sociales" (p. 101). Interesa su perspectiva por cuanto busca desbordar los exterminios exclusivamente físicos y psíquicos para considerar los blancos histórico-sociales, y agregamos, con epicentro en las construcciones culturales-populares evidentes en el caso. Sin normativa que aún encuadre estos debates (sustancialmente en el campo jurídico), la definición más acabada sobre genocidio cultural resulta del "Informe sobre la prevención y sanción del crimen de genocidio" redactado en 1985 por Benjamin Whitaker, relator especial designado por la Subcomisión de Prevención de Discriminaciones y Protección a las Minorías, subórgano de las Naciones Unidas; a saber:"[...] todo acto premeditado cometido con la intención de destruir el idioma, la religión o la cultura de un grupo nacional, racial o religioso por razón del origen nacional o racial o de las creencias religiosas de sus miembros, actos tales como: 1) la prohibición de emplear el idioma del grupo en las relaciones cotidianas o en las escuelas o la prohibición de imprimir o de difundir publicaciones redactadas en el idioma del grupo; 2) la destrucción de las bibliotecas, los museos, las escuelas, los monumentos históricos, los lugares de culto u otras instituciones y de los objetos culturales del grupo o la prohibición de usarlos".

6. Aquella noche secuestraron a: Francisco Routaboul (síndico), Renato Perrota (revisor de cuentas), Platón Duri (síndico), Augusto Duri (presidente de CD), Omar Pérez Cantón (revisor de cuentas), Alberto Pedrido (tesorero), Raúl Frutos (vicepresidente y bibliotecario mayor) y Domingo De Nichilo (revisor de cuentas). El grupo fue traslado al Servicio de Informaciones ubicado en la Jefatura de Policía de Rosario donde funcionó el Centro Clandestino de Detención y Tortura "El Pozo". Permanecieron en carácter de desaparecidos durante noventa días aproximadamente. A posteriori fueron declarados como detenidos del Poder Ejecutivo Nacional, siendo finalmente liberados el 24 de diciembre de 1977 sin imputación de delito alguno.

7. Infra apartado "El Expediente Judicial: una confesión de partes".

8. Los directores de curso fueron implementados desde el año 1970 en el Instituto Secundario. Eran profesores con formación terciaria y universitaria dedicados a acompañar pedagógicamente a los alumnos en su tarea cotidiana estimulando la comprensión de los contenidos y bajo una alta consideración de sus historias de vida. Durante el ciclo básico que se extendía hasta el 3er año, se propiciaban herramientas estratégicas de aprendizaje mediante un espacio curricular denominado "Estudio dirigido". En el ciclo superior, la propuesta se orientaba a brindar una "Orientación emocional". Estos programas buscaban configurar un espacio específico para la discusión grupal, el debate e intercambio de opiniones respecto de asuntos institucionales, disciplinarios o del interés de los alumnos.

9. En referencia al denominado movimiento Escuela Nueva gestado por reconocidos educadores y pensadores europeos (Tolstoi, Decroly, Freinet, Pestalozzi, Fröbel, Montessori) y de Estados Unidos (E.E.UU.) (Dewey) con marcada influencia en Argentina durante las décadas del 20 y 30 . La vasta bibliografía dedicada a su heterogéneo y desigual impacto, coincide en señalarla como una renovación del pensamiento pedagógico que no logró ir más allá de diversas y aisladas experiencias; esto es, sin articularse en una alternativa al sistema reglado y normativizado de neto corte positivista. Durante la década del 60 y 70, aspectos clave de su propuesta general (centros de interés del alumno; atención a las etapas de desarrollo; docente como auxiliar del aprendizaje; relación democrática intra-áulica; trabajo grupal y cooperativo; ponderación de los conocimientos socialmente significativos; articulación de la vida cotidiana por sobre el enciclopedismo; espontaneismo ordenado; entre otros) se vieron revitalizados en América Latina, acoplados a la psicologización y politización del campo educativo.

10. Entre finales de 1974 y principios de 1977, Biblioteca Vigil sufrió dos atentados explosivos que causaron graves daños en el edificio principal ubicado en la intersección de las calles Alem y Gaboto. En otra oportunidad, y en plena jornada escolar, un auto a gran velocidad abrió fuego de metralla sobre la pared orientada a calle Alem. Finalmente, en horas de la madrugada, un grupo 
de personas encapuchadas amordazó al sereno que custodiaba las instalaciones del sector administrativo. Tras hurgar en toda la documentación existente, en una oficina pintaron: “A.A.A.".

11. En 1964 el profesor y artista plástico Rubén Naranjo, graduado en la Universidad Nacional del Litoral, se sumó a la pujante entidad para dirigir la Escuela de Artes Visuales de la Universidad Popular. De inmediato, se incorporó a la CD. En 1966 tomó a su cargo la extraordinaria experiencia de la Editorial "Biblioteca" y en 1976 asumió como rector del Instituto Secundario.

12. Elba Parolín ingresó a la organización en los primeros años de la década del 70. Formada en las corrientes del movimiento de la Escuela Nueva bajo la dirección de Olga Cossettini durante la experiencia de la Escuela Normal № 204 “Domingo de Oro" de la ciudad de Rafaela.

13. Profesor Titular de Política Educativa en la Facultad de Filosofía y Letras de la Universidad Nacional del Litoral (U.N.L.). Director del Seminario Sociedad y Educación en el Departamento de Pedagogía Universitaria, U.N.L. Profesor de Política Educativa del Profesorado de Ciencias de la Educación de la Facultad de Humanidades y Artes de la Universidad Nacional de Rosario. Director de la publicación Hoja Informativa de la Biblioteca Popular "Bernardino Rivadavia" y escuelas anexas de Villa María (Córdoba).

14. La ex docente Mirtha Taborda recuerda "Yo un día estaba en [bar] "El Cairo" con un amigo y había salido la lista de torturadores de la CONADEP, y cuando vi esos nombres, yo...me desmayé. Cuando vi el nombre Ibarra...”. En entrevista realizada el día 22 de abril de 2011.

15. De acuerdo a la investigación de Águila (2008a) el Servicio de Informaciones ubicado en dependencias de la Jefatura de Policía de Rosario fue el Centro Clandestino de Detención más importante de la región "por su centralidad en el esquema represivo y el elevado número de detenidos" (p. 86).

16. Con el propósito de profundizar las investigaciones judiciales por delitos cometidos por civiles durante el terrorismo de Estado en Argentina, Cristina Fernández de Kirchner firmó en el año 2010 el mencionado decreto; esto es, la desclasificación de la nómina del Personal civil de Inteligencia (PCI) que colaboró en tareas de censura, persecución ideológica y delación de militantes de organizaciones políticas, sindicales y sociales. De los 4.300 agentes que hasta la fecha se individualizan y documentan, 116 agentes se desempeñaron en Rosario y su amplia zona de influencia. Para el caso de Carlos Sfulcini, se comprueba su inclusión como tal bajo el número № 4274, fs. 80 de la Dirección General de Inteligencia.

17. Raúl Pangia, “Agente de censura”, PCI № 4274, fs. 80. Dirección General de Inteligencia.

18. Sucintamente, cabe explicitar que los testimonios de ex alumnos y ex docentes que atravesaron el periodo intervencionista en el Instituto Secundario, dan sobradas muestras de prácticas de persecución ideológica, espionaje, "interrogatorios" con ostentación de armas y hostigamiento individualizado que al presente no solo perduran como huellas traumáticas subjetivas, sino que se inscriben como delitos de lesa humanidad que a la fecha se investigan en la causa judicial que igualmente indaga en el desguace patrimonial. Véase: http:// www.pagina12.com.ar/diario/suplementos/rosario/9-31061-2004-01-05.html; $\quad$ y: $\quad$ http:// www.pagina12.com.ar/diario/suplementos/rosario/9-36405-2012-11-12.html.

19. En rigor, dicha problemática se encuentra en un estadio embrionario en los estudios de historia reciente sobre el campo educativo. Por fuera de los trabajos ya citados de Kaufmann (2001, 2003, 2006) debe considerarse aquí la investigación de Rodríguez (2012) sobre el rol de los funcionarios civiles en las políticas educativas de la última dictadura para el caso de la provincia de Buenos Aires. Sobre el particular, la autora sintetiza "también hubo docentes que aceptaron actuar el rol de 'interventores' del establecimiento adonde trabajaban y avalar -por acción u omisión- la expulsión de colegas con los que compartían el mismo espacio escolar" (p. 51). En el caso de la Biblioteca Vigil, y en términos generales, se dio una coyuntura diferente sin dudas relacionada con la historia e identidad institucional; como se dijo, el cuerpo docente se vio diezmado entre persecuciones ideológicas y terror amenazante, al tiempo que un grupo 
minoritario permaneció en sus funciones tras la intervención. Precisamente, la permanencia en su lugar de trabajo fue significada en su contexto como un acto de "resistencia" solapada a los efectos de "cuidar" a la escuela y más aún a sus alumnos.

20. Surge el día 11 de marzo de 2004 conformada por ex dirigentes, ex empleados, ex docentes, ex alumnos y vecinos de la emblemática biblioteca, con los siguientes objetivos: restitución de la personería jurídica a sus legítimos dueños; restitución de los bienes muebles e inmuebles; investigación de todo lo actuado durante la liquidación; determinación de las responsabilidades de los interventores civiles y militares.

21. La denuncia realizada por la Asamblea de Socios de Biblioteca Vigil en el año 2004, fue dirigida al interventor-liquidador Dr. Emilio Echen y contador Jorge Menegozzi "por irregularidades observadas en la tramitación de la causa de referencia por presunta comisión del Delito contemplado en el Art. 173 inc. 7" del Código Penal. Ambos renunciaron a sus funciones. Desde entonces el proceso fue controlado por un nuevo interventor enviado desde el Instituto Nacional de Asociativismo y Economía social (I.N.A.E.S.) y la parte denunciante.

22. Tras poco más de tres décadas intervencionistas, en noviembre de 2008 se dicta la resolución № 2.430 firmada por el Directorio del I.N.A.E.S., ex I.N.A.M. disponiendo la conclusión del proceso liquidatorio. Sobre el particular, véase García (2012).

23. En una evidente continuidad histórica, y más aún desde mediados de los 80 , el barrio "Tablada" ocupa un espacio predilecto en la sección "policiales" de los diarios locales bajo rojos titulares que repiten "delincuencia", “droga", "menores" e "inseguridad". Solo la experiencia de "la Vigil" materializó largas editoriales periodísticas en la sección "Cultura y sociedad".

24. "Inauguraron El Complejo Pedro De Vega", diario La Capital, Rosario, 13/9/81.

25. En entrevista realizada el día 02 de octubre de 2009, el ex tesorero Tomás Pedrido, nos comenta: "Rubén se fue, lo fueron a buscar encapuchados, lo hubieran matado". La ex docente y artista Liliana Herrero amplía en su testimonio: "Nosotros estábamos en casa durmiendo y tocan el timbre. Era Rubén Naranjo con una de sus hijas [...] Nos levantamos y Rubén nos dice que la policía estaba levantando a toda la Comisión Directiva de 'la Vigil'. Bueno, ahí nos dice que él se va a esconder. No preguntamos en qué lugar; no era conveniente saber. Luego por supuesto supimos que amigos lo habían escondido en Rosario y luego, evitando los piquetes policiales en la ruta 9, se había ido a Buenos Aires". En entrevista realizada en junio 2011.

26. Alcides Ibarra se interesó especialmente por la mecánica de préstamos y consultas del acervo bibliográfico solicitando información sobre la masa de lectores, a los claros efectos de rastrear y relacionar centenares de nombres y domicilios de los usuarios con literatura considerada subversiva.

27. En relación a la influyente obra del pedagogo brasileño Paulo Freire durante los primeros años de la década del 70 .

28. Diario Rosario/12, Rosario, Junio 12.

29. Antes de su fallecimiento en el año 2010, realizamos una larga entrevista con el profesor Edgardo Ossanna y le acercamos la documentación mencionada previa autorización para la búsqueda y publicación de datos. Sorprendido y conmovido nos comentó cuán insospechado le resultaba todo ello. Aun cuando sufrió la cesantía en otros establecimientos escolares, no imaginó que sobre él se realizaran tareas de inteligencia desde el año 1970, según puede leerse en la ficha en cuestión.

30. "Cuaderno de comunicación de novedades mensuales del personal interino (1981/1982)".

31. Para la mencionada especialista, reordenar una archivalía equivale a restituirle su orden original siguiendo la lógica de su propia producción. Denomina "justiciero ordenamiento" a la práctica habitual de hacerlo en virtud de nuestras orientaciones políticas y en perjuicio de los fondos documentales. Desde ya, Nazar establece antes la diferencia entre "trabajar" e "investigar" en un archivo. Precisamente, nuestra tarea solo se limitó a lo segundo; no obstante, la forma de apropiarnos de estas fuentes remite a su concepto y advertencia. 
32. Miembro de la Congregación de las Hermanas Franciscanas Terciarias Misioneras. Ciertamente, este dato, aunque accesorio al análisis en cuestión, no resulta menor en la historia de la institución en general, por cuanto las relaciones entre la Iglesia católica argentina y Biblioteca Vigil fueron crecientemente tensas; en particular, desde la llegada de Monseñor Guillermo Bolatti como Obispo de la ciudad de Rosario (1963) y profundizándose en los primeros años de la década del 70 en oportunidad de tramitar ante la Superintendencia Nacional y Provincial de Enseñanza Privada los planes de estudio, habilitaciones edilicias y pedidos de subsidios económicos para las escuelas formales de "Vigil". Siguiendo los testimonios de dirigentes y directivos escolares, el poder lobista del Consejo Superior de Educación Católica (CONSUDEC) como expresión de un potente conservadurismo pedagógico, produjo graves obstáculos y trabas burocráticas, al tiempo que, desde los púlpitos locales, se condenaba a la organización por su férreo laicismo sembrando sospechas de una "infiltración comunista". En suma, la presencia de directivos y docentes afines o miembros del clero católico en el "converso" Complejo Pedro de Vega (según se sigue en los legajos de docentes ingresantes desde la intervención), habilitan inferir una intervención de la moral católica largamente temida por los dirigentes de "la Vigil".

\section{RESÚMENES}

En 1977 se produce la intervención cívico-militar sobre la Biblioteca Popular "Constancio C. Vigil" de Rosario. En el marco de una investigación académica (2007-2012), se encontraron inéditas fuentes documentales primarias que permitieron profundizar, tensionar y/o producir nuevos conocimientos sobre el caso inscripto en la historia reciente de la educación argentina. El componente novedoso del corpus se anuda a la potente representación de un desierto documental producto de la férrea intervención dictatorial. En este artículo se presentan los acervos aludidos detallando sus principales características; espacios de producción histórica; localización; tiempo de recolección; contenidos y efectos metodológicos. Igualmente, se profundiza en las circunstancias de cada encuentro y particularidades de su acceso, seleccionando específicas fuentes que evidenciaron rupturas y continuidades en una dimensión disciplinaria micro y macro. Finalmente, señalamos los interrogantes a los que se dará respuesta y que surcan con sentido la trama descriptiva del artículo: ¿Por qué -aparentemente- el caso se mueve desde el silencio documental a la proliferación de fuentes escritas? Dicha emergencia ¿responde solo a un tiempo sociopolítico favorable a una revitalización de las memorias y/o estudios sobre el pasado reciente?

In 1977 there was a civil-military intervention on the Popular Library "Constancio C. Vigil" ( Rosario, Argentina). As part of an academic research (2007-2012), we found unpublished primary source documents that made possible the production of new knowledge about the case registered in the recent history of education. The new component of the corpus becomes meaningful as contrasted with the supposed documentary void during the dictatorship. This article presents these collections specifying its main features; spaces of historical production; location; time of collection; content and methodological effects. It also delves into the circumstances of each finding and particularities of their access, selecting those sources that evidenced interruptions and continuities in the different dimensions of the discipline (macro and micro). Finally, we define the questions that will be answered and which give sense to the article: Why-apparently 
-the case moves from the void into the proliferation of written sources? Does such emergence respond only to a sociopolitical time that favors the refreshment of memories and/or studies of the recent past?

ÍNDICE

Keywords: Archives, memories, civil-military institutional intervention, history of education Palabras claves: Archivos, memorias, dictadura cívico-militar, intervención institucional, historia de la educación

\section{AUTOR}

\section{NATALIA GARCÍA}

Instituto de Investigaciones. Facultad de Humanidades y Artes. Universidad Nacional de Rosario. Consejo Nacional de Investigaciones Científicas y Técnicas, Argentina.

Correo electrónico: nataliagr5@gmail.com 